\title{
Secuencia constructiva de la iglesia de Nuestra Señora de Campanario en Almazán (Soria). Datos para la interpretación de sus estructuras románicas
}

\author{
Constructive secuence of the church of Nuestra Señora de Campanario \\ in Almazán (Soria). Data for the interpretation of its Romanesque structures
}

\author{
Francisco J. Moreno Martín \\ Universidad Complutense de Madrid. \\ e-mail: franciscojose.moreno@ghis.ucm.es \\ José Ignacio Murillo Fragero \\ Urbe pro Orbe. Madrid. \\ e-mail: jimurillo@urbeproorbe.com
}

\section{RESUMEN}

Se exponen los principales resultados obtenidos tras la lectura estratigráfica de un templo que, pese a su escala, ha suscitado un moderado interés en los estudios del románico soriano. La secuencia, que se prolonga hasta nuestros días, arroja interesantes datos acerca de un posible proceso de fortificación en época medieval así como sobre las dificultades experimentadas para su cierre definitivo. La imbricación de los datos arqueológicos con las referencias escritas conservadas nos ha permitido, además, documentar las intensas remodelaciones de la fábrica en la edad Moderna.

Palabras clave: Arqueología de la arquitectura; románico; iglesia fortificada.

\section{ABSTRACT}

This paper shows the main results of the archaeological analysis of a temple which, small though, has caused a moderate interest within the studies on the Romanesque in Soria. The sequence, which lasts until today, offers interesting data regarding a possible fortification process in the medieval period and the obstacles to close it up definitely. The archaeological data along with the written references have made possible besides to record others deep transformations that took place in the Modern Age.

Keywords: Archaeology of the architecture; Romanesque; fortified church.

Recibido: 26 mayo 2014. Aceptado: 18 julio 2014.

Cómo citar este artículo / Citation

Moreno Martín, F. J. y Murillo Fragero, J. I.: "Secuencia constructiva de la iglesia de Nuestra Señora de Campanario en Almazán (Soria). Datos para la interpretación de sus estructuras románicas", Arqueología de la Arquitectura, 11: e020. doi.org/10.3989/arq.arqt.2014.174.

\section{Copyright}

(c) 2014 CSIC. Este es un artículo de acceso abierto distribuido bajo los términos de la licencia Creative Commons Attribution-Non Commercial (by-nc) Spain 3.0. 


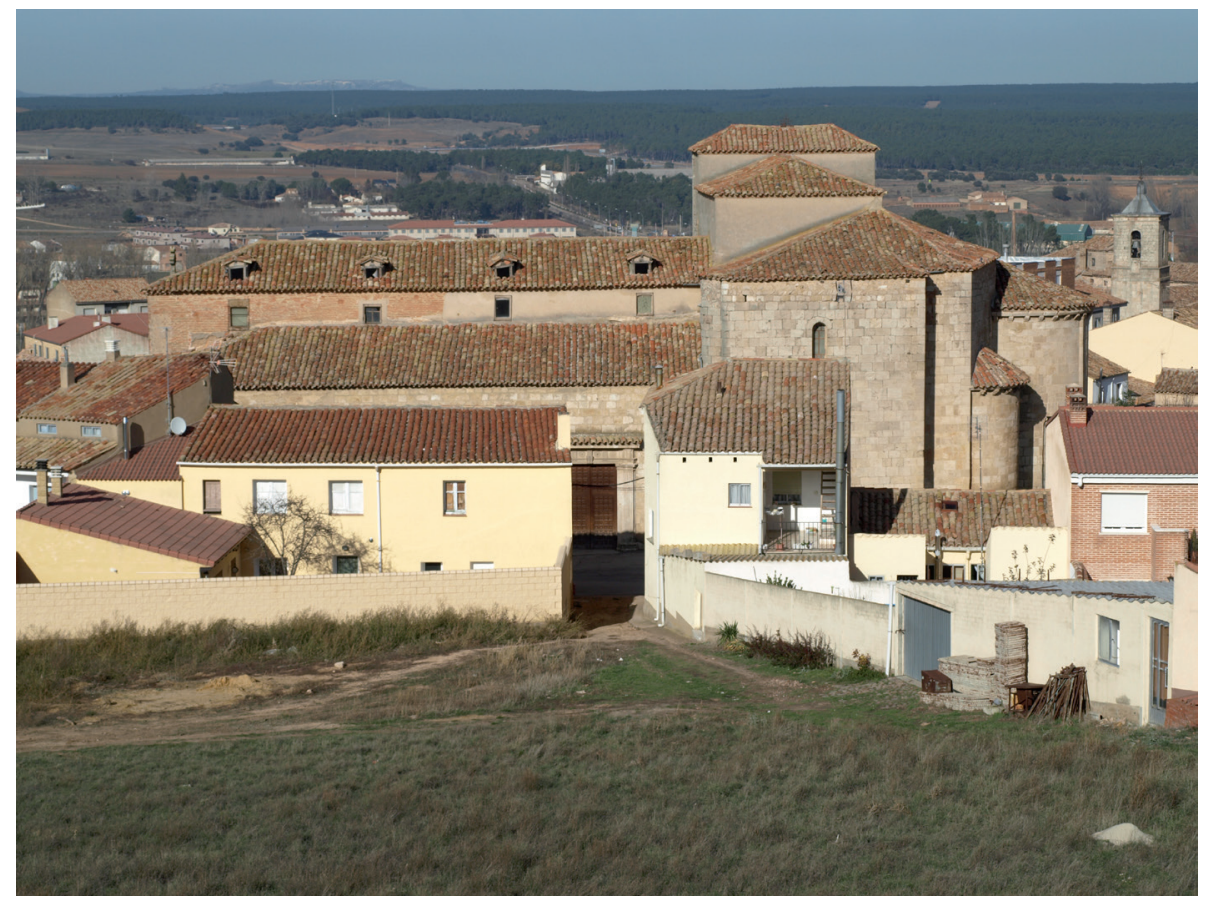

Fig. 1. Imagen del templo desde el cerro del castillo

\section{1.- Introducción}

«(...) situada en el punto sur mas elevado del pueblo, de solidez pero muy deforme a la vista, y de malas proporciones en el interior: mas parece una fortaleza que un templo...» (Madoz 1845: 77).

La denigrante categorización que ciertos eruditos decimonónicos vertieron sobre este edificio parece haberlo estigmatizado incluso hasta nuestros días (Fig. 1). Pese a poder considerarlo como uno de los monumentos medievales más interesantes de la provincia de Soria, lo cierto es que apenas recibe atención por parte de quienes llegan hasta la localidad de Almazán. Situada al pie de la desaparecida fortaleza adnamantina, la iglesia de Nuestra Señora de Campanario observa irremediablemente cómo el interés del visitante se concentra en la zona más próxima al Duero, donde fueron levantados el palacio de los Mendoza y la también iglesia románica de San Miguel.

Su imponente fábrica se alza por encima del caserío mostrando altiva una interesantísima sucesión de elementos de variada adscripción. La parte más antigua es, tal vez, la de mayor nobleza material. La cabecera triple de ábsides semicirculares y el transepto a la que abren fue levantada en sillería bien escuadrada. El aula, con sus tres naves, muestra una mayor humildad exterior. $\mathrm{Si}$ acaso los accesos del sur y del norte -este hacia el centro de la población- son la única concesión monumental (Fig. 2). El crucero, decorado en su interior, pasa desapercibido al exterior merced a la existencia de muros de diferente factura que afean la silueta, entre ellos la esbelta espadaña que da nombre al edificio ${ }^{1}$. La conjunción de estos factores, sumada a la casi total ausencia de restauraciones «en estilo», auguraba la presencia de una rica secuencia constructiva que pudo ser corroborada a través del análisis estratigráfico.

Desde una perspectiva metodológica, el desarrollo global de los trabajos se inserta dentro de los planteamientos establecidos por la Arqueología de la Arquitectura, si bien con una particularidad. Para el estudio de los alzados interiores de las naves y el coro fue preciso acudir a la estrategia denominada «análisis configuracional» (Mannoni 1998). Los revoques en esta zona impedían documentar la secuencia estratigráfica, de manera que se procedió a la realización de una tabla de variables tipológicas de

\footnotetext{
1 Acerca de su curiosa advocación se pronunció Ortego (1973: 58) suponiendo que el origen de tal dedicación podría deberse a la existencia previa de una mezquita a cuyo alminar, convertido posteriormente en campanario cristiano, se adosaría la iglesia románica. Sigue esta idea Sainz (1984: 526), si bien responsabiliza a la tradición oral el recuerdo del desaparecido alminar. Más prudente se muestra Rodríguez (2002: 150) al considerar que este nombre viene dado de la presencia de la espadaña, considerada gótica en su trabajo, sobre el brazo norte del transepto. Del estudio documental realizado a raíz de nuestra intervención solamente podemos deducir que tal denominación estaba ya en uso a mediados del siglo XIV, puesto que así aparece mencionada en un inventario de las iglesias de la diócesis de Sigüenza en el año de 1353 (Minguella 1912: 343).
} 


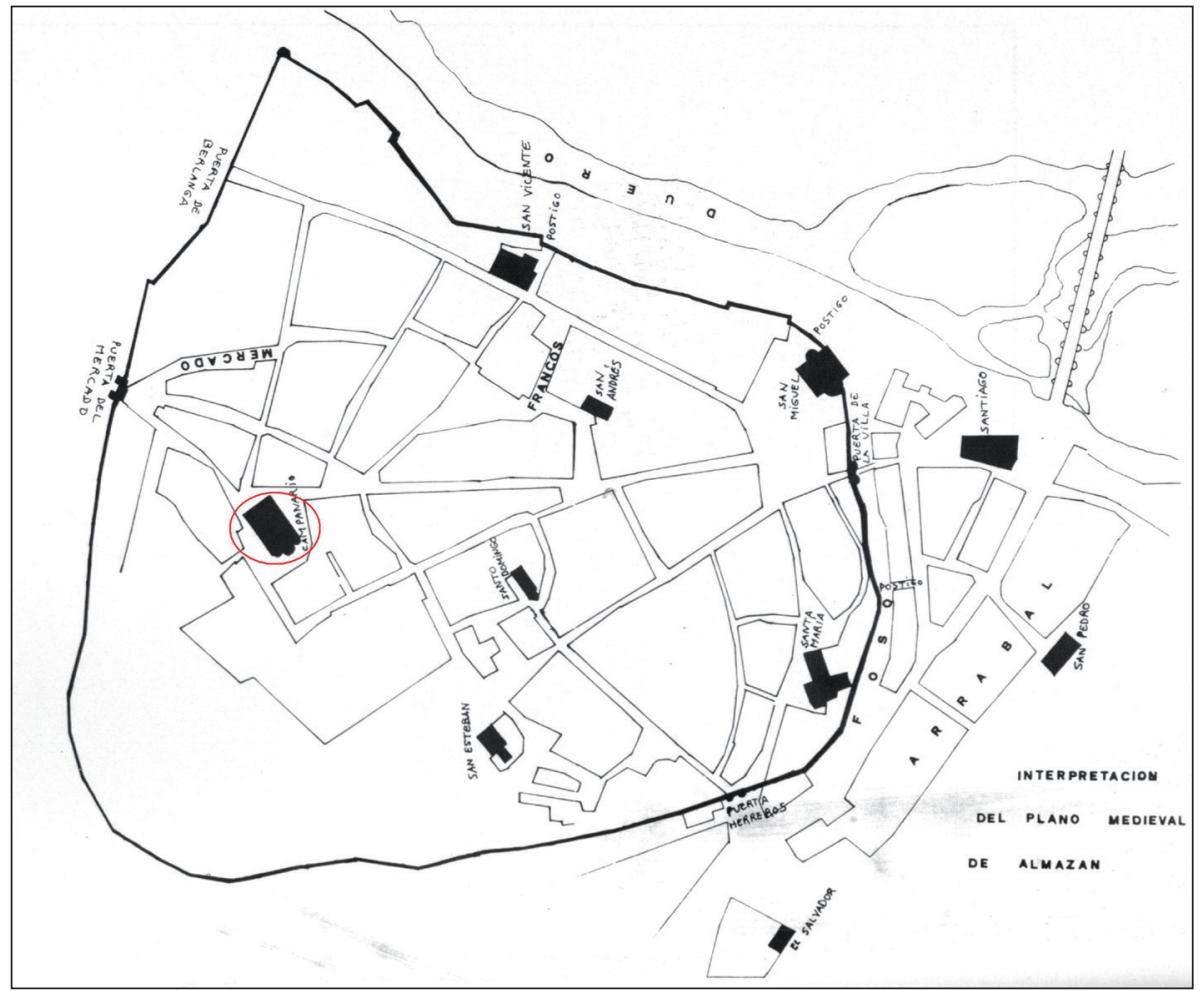

Fig. 2. Topografía medieval de Almazán donde se señala la ubicación del edificio (Márquez 1987) los elementos singulares (basas, pilares, ménsulas y plafones). Esto permitió establecer áreas de convergencia/ divergencia para una posterior reconstrucción secuencial de las zonas cubiertas por los enlucidos.

\section{2.- Historia de la investigación}

Sea por su ecléctica naturaleza, sea por desconocimiento, lo cierto es que el interés mostrado hacia este edificio ha sido moderado. En el siglo XIX no pasó de ser catalogada como de origen gótico con añadidos que «forman un todo desagradable» (Madoz 1845: 77), quizás por su falta de adscripción estilística bajo postulados positivistas. Entrados en el siglo XX, sería Gaya (1946: 185) quien procediera con una pormenorizada descripción de su parte románica y un primer encuadramiento cronocultural sobre la base de un intento de recomposición evolutiva. En su opinión, románicos — si bien de fechas avanzadas en el desarrollo de este estilo ${ }^{2}$ - son tanto

\footnotetext{
2 Considera el conjunto ornamental (básicamente capiteles, impostas, ménsulas y canecillos) una variante del expuesto en la iglesia de San Miguel también en Almazán. La bóveda ojival en el crucero y las ménsulas de raigambre cisterciense son, junto con la disposición de las cubiertas de cañón apuntado en el transepto, las características que le permiten situar este templo en la frontera entre los siglos XII y XIII. Por tanto, obra de transición entre el románico y el gótico (Gaya 1946: 186).
}

la cabecera como el transepto, excluyendo por razones tipológicas el aula, que considera de época moderna.

A partir de este trabajo, y hasta el reciente siglo, apenas hay estudios que superen lo expuesto, al menos en lo referido a la construcción románica. Abundan las guías locales con informaciones superficiales e inexistente aparato crítico que insisten en las conclusiones de Gaya (Taracena y Tudela 1962: 191; Alcolea 1964: 107; Pérez-Rioja 1970: 114; Ortego 1973: 57; Sáinz 1984: 523-525; Huerto y Frías 1991: 22; Herrero y Márquez 1994: 16).

De mayor profundidad y relevancia es el artículo recogido en el volumen que dedica a Soria la Enciclopedia del Románico. En este trabajo se habla de la iglesia como el proyecto más ambicioso de la población. Un proyecto románico que se considera inacabado, pues sólo la cabecera y los muros perimetrales del transepto entran dentro de los parámetros formales fijados para este estilo (Rodríguez 2002: 150). También se dan a conocer los espacios bajocubierta en la cabecera, si bien la acumulación de material impidió el adecuado acceso y la recogida de datos que hubiera permitido emitir hipótesis acerca de su posible función. La cronología románica tardía propuesta por Gaya se ve refrendada aquí mediante la datación de una escultura catalogada como «borgoñona» (Rodríguez 2002: 153). 
Pese a resultar lógico el interés demostrado por las fases románicas del edificio, la desatención hacia el resto de sus componentes ha favorecido el mantenimiento de un interrogante fundamental hasta la actualidad: $¿$ se llegó a concluir la gran iglesia románica? Veamos aquí algunas de las propuestas al respecto.

Sin aportar datos documentales, son varios los autores que hablan de añadidos en época moderna (Taracena y Tudela 1962: 191; Alcolea 1964: 107; PérezRioja 1970: 114). Sin embargo, no tardarán en aparecer análisis que reclamen la existencia de una fase gótica intermedia especialmente visible en los restos de la desmontada capilla norte llamada de los Laynez ${ }^{3}$, así como en la cubierta de terceletes del crucero, datada a través del análisis estilístico y heráldico en la segunda mitad del siglo XV (Martínez 1980: 406). Para Rodríguez (2002: 150), el hecho de que las bóvedas del transepto cubran parcialmente las ventanas románicas del cimborrio apoyaría una cronología gótica también para dichas cubiertas ${ }^{4}$.

La constatación de una etapa intermedia bajomedieval entre la primera fábrica románica y el aula moderna sirve como punto de apoyo para el establecimiento de la siguiente secuencia; la obra románica se detendría en los pilares orientales del crucero para ser retomada en el entorno del 1500, siendo remozada el aula en los siglos XVII y XVIII (Rodríguez 2002: 154). Esta es, hasta el momento, la propuesta evolutiva de mayor precisión $\mathrm{y}$, como hemos visto, está fundamentada en el análisis formal combinado con el uso de las escasas referencias textuales. Nuestra labor aporta a lo ya expuesto una visión estratigráfica y tipológica acompañada de la revisión de la documentación conservada. Como veremos a continuación, a partir del trabajo efectuado estamos en disposición de matizar algunos de estos aspectos.

\footnotetext{
3 Hacen referencia a esta capilla Huerto y Frías (1991: 22) y Rodríguez (2002: 154). Fue mandada construir por Hernán Laynez y su hijo Diego, bisabuelo y abuelo del padre Laynez (1512-1565), famoso jesuita adnamantino que participó activamente en el concilio de Trento, segundo general de la Compañía y biógrafo de San Ignacio de Loyola. Resulta interesante contextualizar la construcción de esta capilla, en el que, no debemos olvidar, fue uno de los templos más importantes de Almazán, por parte de una familia de conversos que abrazan tardíamente el cristianismo, tal y como puso de manifiesto Diago (1993: 250, nota al pie). Cabe pensar que este patrocinio fuera una de las fórmulas a través de las cuales afianzar su posición privilegiada dentro de la comunidad de cristianos de la villa. Herrero y Márquez (1994: 16) publican la noticia documental de su desmonte en el año 1762 al no subsistir ningún familiar de los fundadores que pagara las rentas.

4 Aunque no le falta razón en el establecimiento de dicha relación, como tendremos oportunidad de explicar, toda la estructura del cimborrio debió ser reconstruida a lo largo del siglo XIX.
}

\section{3.- La construcción del edificio románico}

La primera conclusión que se desprende del análisis de sus paramentos es que, al menos por encima de la cota 0 , la parte más antigua del templo corresponde a la actual cabecera tripartita y el transepto que la precede (A 100), no habiéndose registrado ningún elemento en alzado que permita suponer la existencia de estructuras anteriores ${ }^{5}$. Se trata de un ambicioso proyecto constructivo desarrollado a escala monumental, como testifica la conservación de los tres ábsides de planta semicircular dispuestos en batería que abren hacia una nave transversal o transepto destacado, pues corre perpendicular a las trazas conservadas del muro originario sur del aula (A 101).

Como hemos señalado más arriba, el análisis formal efectuado por quienes nos han precedido les llevó a considerar todo el sector oriental del templo, desde el transepto hasta el hemiciclo del ábside central y desde los zócalos hasta las cubiertas, como parte de un mismo proyecto de transición hacia el gótico (Fig. 3). Sin embargo, la observación detenida de sus características materiales y las relaciones estratigráficas de las unidades que lo conforman nos proporcionan argumentos para matizar esta idea.

\section{Etapa I. Elevación de la cabecera y trazado del transepto.}

La primera etapa constructiva estaría formada por una gran unidad cuyos límites hemos establecido, en el exterior, hasta la cornisa en los ábsides y hasta una altura aproximada de 19 hiladas en el transepto (A 100, UE 1000). Para su edificación se levantaron muros de doble hoja en los que se utilizan sillares de piedra caliza, tallados con hacha y dispuestos a soga, preferentemente, formando hiladas muy regulares con una altura máxima de $40 \mathrm{~cm}$. Sus aristas, en ocasiones, muestran numerosos tajos y están ciertamente escantilladas. Entre las juntas podemos apreciar un mortero arenoso con desgrasantes. La superficie, además de las huellas de talla, muestra numerosas marcas de cantero con variables sencillas entre

\footnotetext{
5 Esta observación es pertinente puesto que contamos con noticias respecto a la actividad en la villa desde la alta Edad Media. Fundación islámica del siglo IX o X (Márquez 1987: 23; Ortego 1973: 11), sabemos que estaba en manos cristianas en tiempos de Fernando I. Durante el reinado de Alfonso VI se produce la donación de una iglesia dedicada a San Félix y a Santa María al monasterio de San Millán de la Cogolla (Márquez 1987: 25, n. 26; Rodríguez 2002: 129).
} 


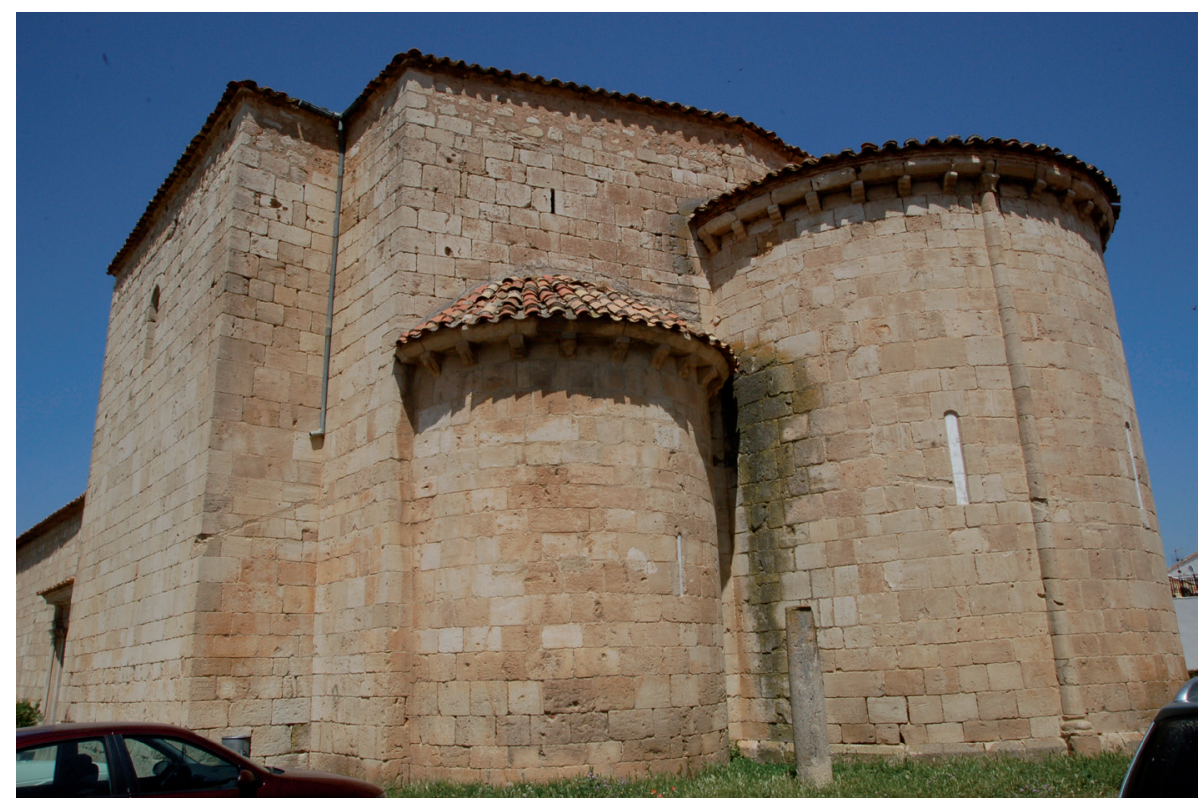

Fig. 3. Exterior de la cabecera románica

las que abundan aspas, cruces, flechas y escuadras. La ausencia de estos signos lapidarios será, además de otros argumentos, uno de los discriminantes para establecer una segunda etapa constructiva.

Al exterior, la cabecera resulta de gran monumentalidad. El ábside central, sobre un zócalo resaltado de poco más de medio metro de altura, es el más complejo en cuanto a su articulación externa. Dos semicolumnas surcan verticalmente sus paramentos para dividirlo en tres paños, en cada uno de los cuales se abren sencillos vanos de medio punto asaeteados. De extrema sobriedad decorativa, solamente podemos mencionar en este ámbito los sencillos capiteles vegetales que rematan las columnas y una corona de canecillos que son modillones de rollo.

Llama poderosamente la atención el que los ábsides laterales se unan al central a través de un pequeño paño recto de menos de $30 \mathrm{~cm}$ de anchura. Comparten con este algunos elementos como el zócalo y la sencillez de los vanos, únicos en este caso y a eje, en la capilla norte, y ligeramente descentrado, en la sur. Aunque hoy se encuentre liberada, gran parte de la cabecera estuvo durante largo tiempo oculta tras estructuras posmedievales, de las cuales todavía se observan sus huellas.

Las características materiales y técnicas presentes en los hemiciclos de los ábsides laterales se prolongan por los muros exteriores de sus respectivos tramos rectos, así como por las partes bajas del transepto, lo que permitió definir sus límites en esta primera etapa (Fig. 4). Tanto en su lado norte como en el sur se alzaba, al menos, hasta la decimonovena hilada y en ambos casos el muro se retranqueaba en la parte occidental para encontrarse con los del aula, lo cual nos permite hablar de un transepto destacado en planta para este primer proyecto. De las naves al exterior, tan sólo hemos podido documentar su arranque hacia los pies en el costado meridional, si bien es un dato importante porque, combinado con otros procedentes del interior, nos permite asegurar que este primer proyecto contemplaba la construcción de un aula de notable anchura apta para una división en tres naves.

En el ángulo suroeste del brazo sur de esta auténtica nave transversal se construyó un husillo circular con una escalera de caracol interna que, en la actualidad, sirve para acceder al bajocubierta de la cabecera (Fig. 5). Pudimos observar cómo, en el exterior, las hiladas inferiores de su paramento traban con las del transepto y sus sillares comparten con los de aquel las mismas características materiales. Estas circunstancias se aprecian tanto en el interior de la iglesia como del propio husillo, al menos hasta cierta altura. En esta zona son visibles marcas de cantero coincidentes con las presentes en los muros externos. Podemos estar seguros por ello de que este proyecto contempló la instalación de un acceso a las partes altas del edificio.

La observación y descripción tipológica de los elementos correspondientes a esta primera etapa resultó trascendental en el interior del templo, puesto que los muros habían sido totalmente picados y las juntas repasadas unificando la superficie (Fig. 6). Las características 


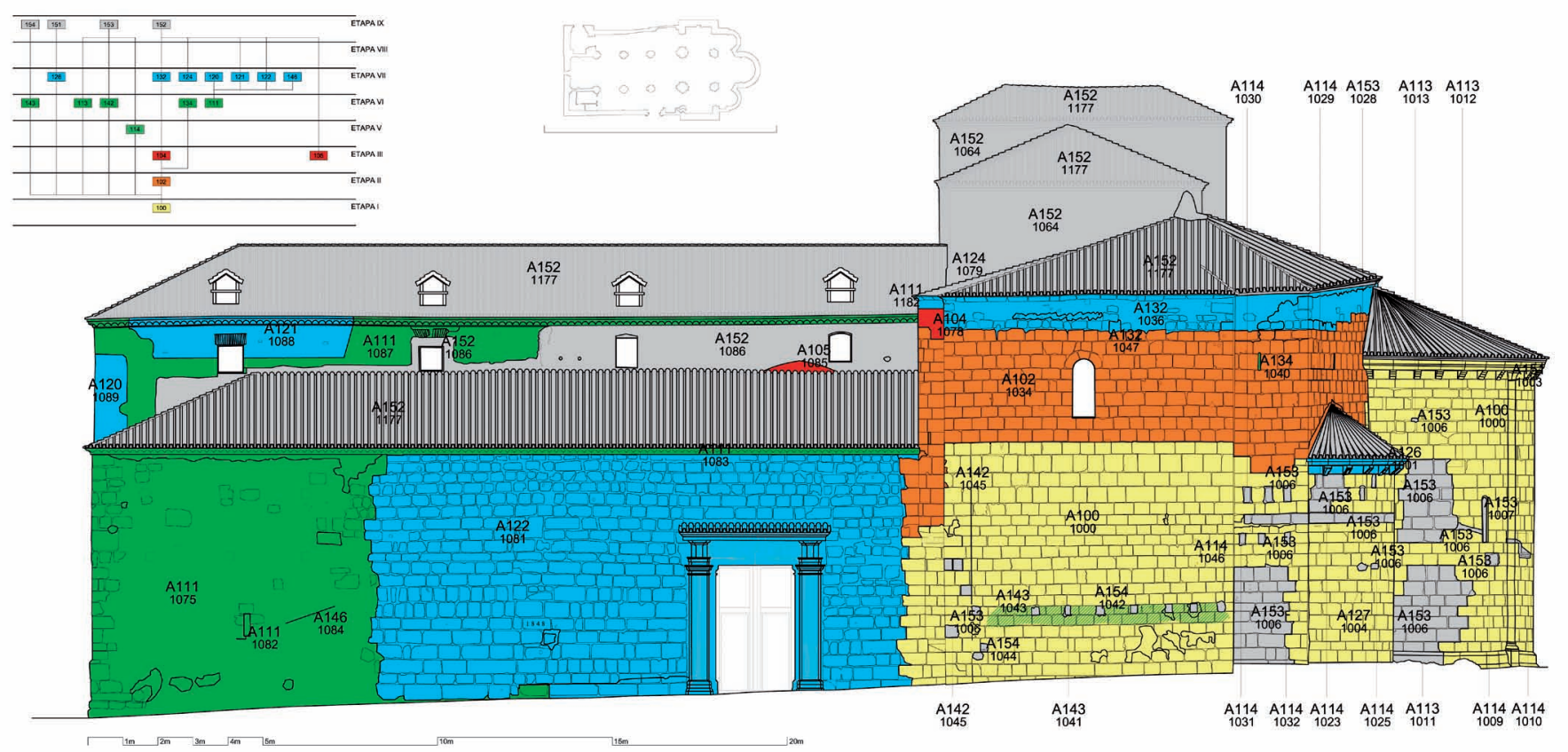

Fig. 4. Alzado sur. Exterior

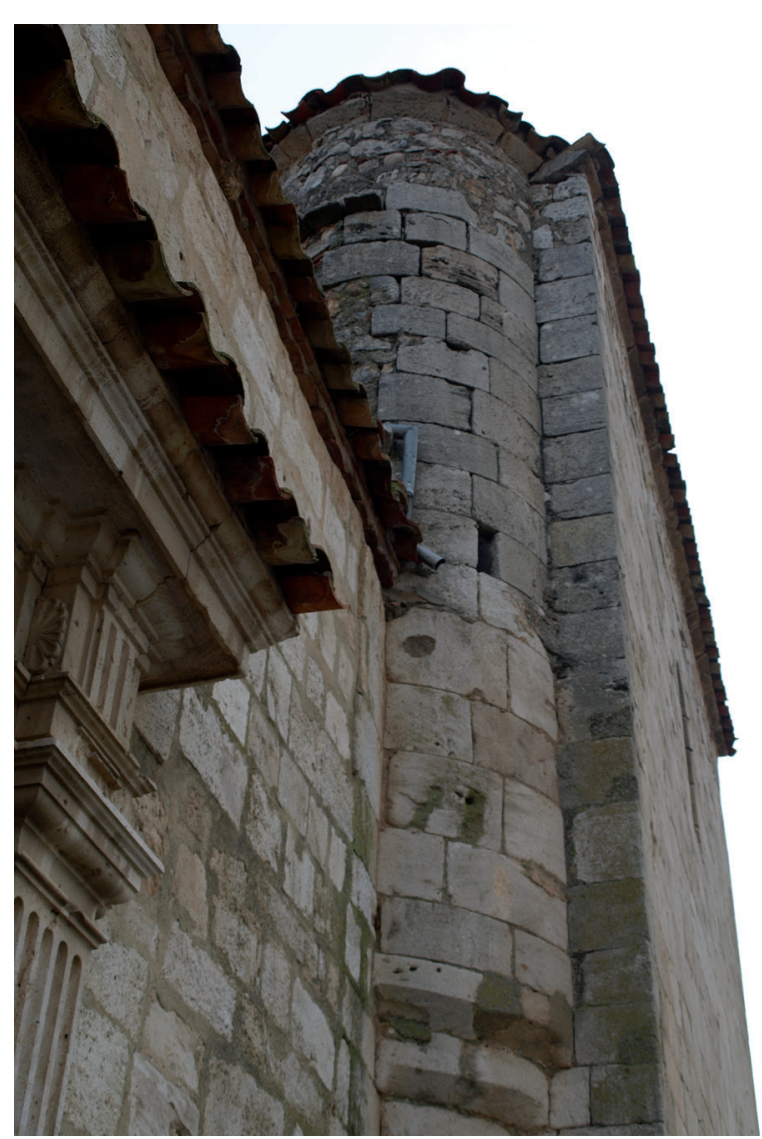

Fig. 5. Husillo en la esquina So del brazo sur del transepto técnicas y materiales utilizadas para establecer los límites del edificio originario al exterior permitieron señalarlos también en el interior. Estos rasgos tipológicos se mantienen de manera constante en todos los muros internos en ábsides y sus correspondientes cubiertas, pero se van diluyendo a distintas alturas en la zona del transepto.

En el muro oriental esta etapa primera se extiende por los tres arcos de embocadura a los ábsides, interrumpiéndose a la altura de la línea de imposta decorada, límite que también es válido para los muros meridional y septentrional. Sin embargo, en el alzado de poniente la UE 1000 (A 100) no alcanza demasiada altura, deteniéndose bajo los arcos de comunicación con las naves laterales. Este mismo cambio se aprecia nítidamente en los pilares compuestos que separan las naves (UE 1140). Pese a las mutilaciones posteriores, todavía es posible reconstruir su imagen primitiva. Se apoyaban sobre basas circulares y poseían núcleo cruciforme con semicolumnas adosadas (Fig. 7). Una estructura, en suma, preparada para recibir los empujes de los arcos formeros y fajones típicos de las estructuras románicas. Sin embargo, a medida que recorremos su superficie en altura, multitud de saltos y cambios de plano permitieron establecer una solución de continuidad que marca la frontera con la siguiente etapa. 

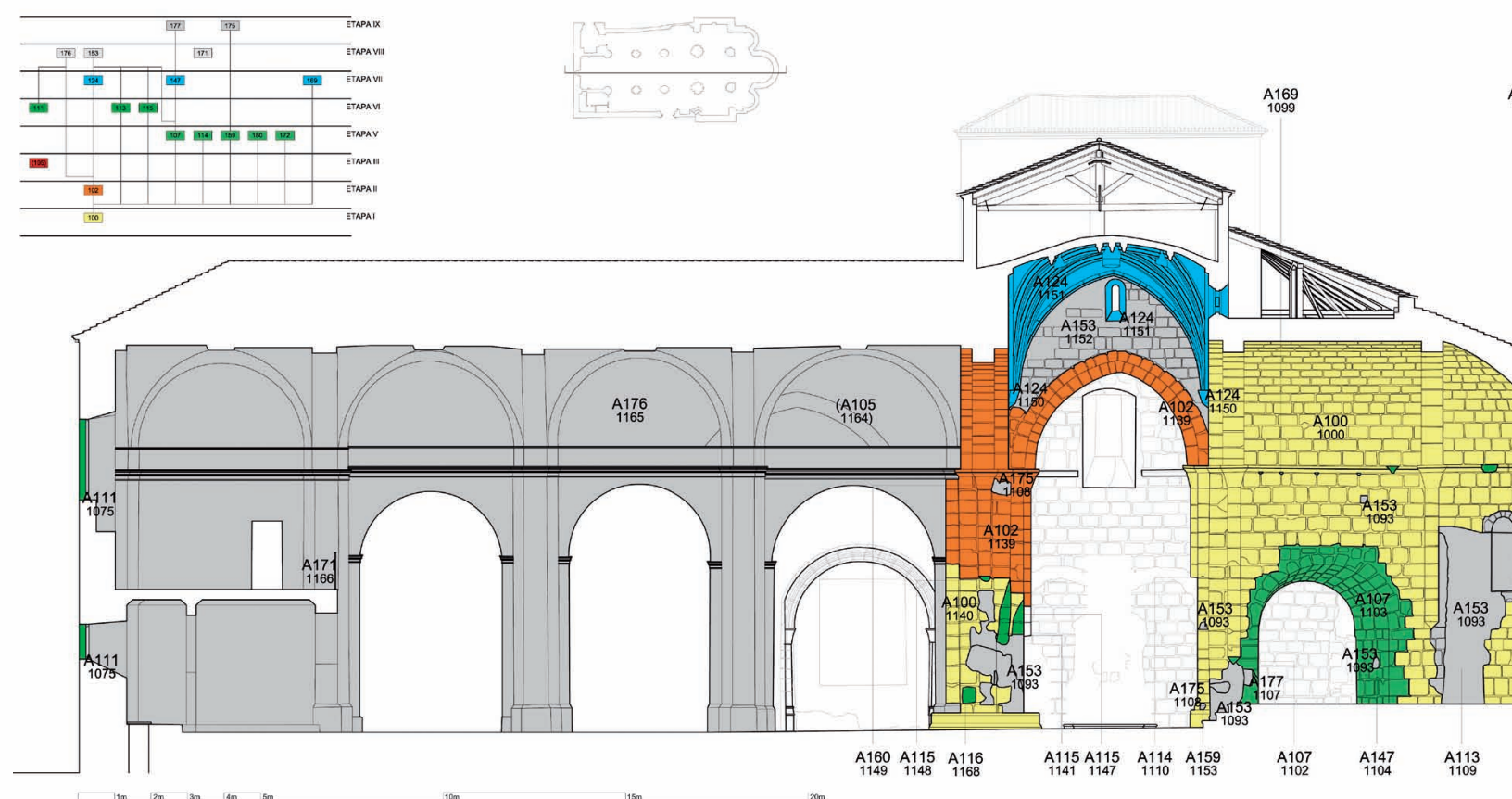

Fig. 6. Alzado interior norte de la nave y ábside central

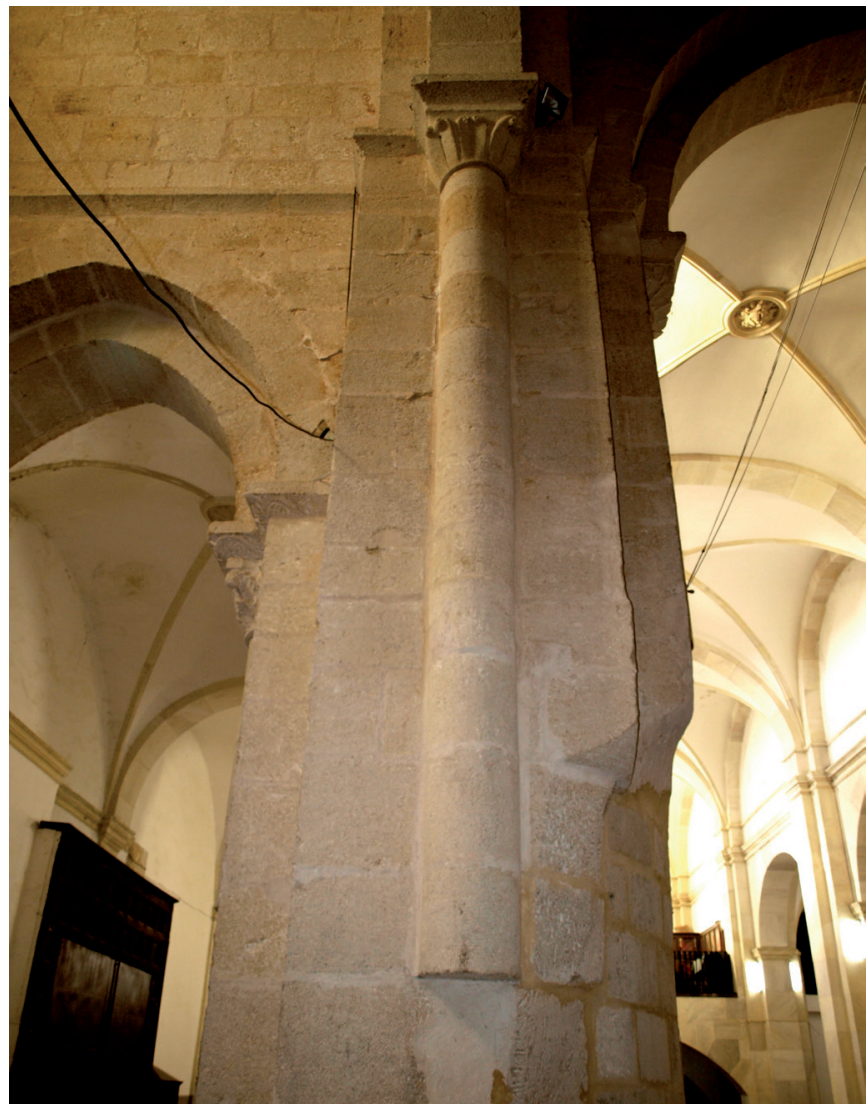

Fig. 7. Detalle de los pilares compuestos de época románica que separan el transepto del aula moderna

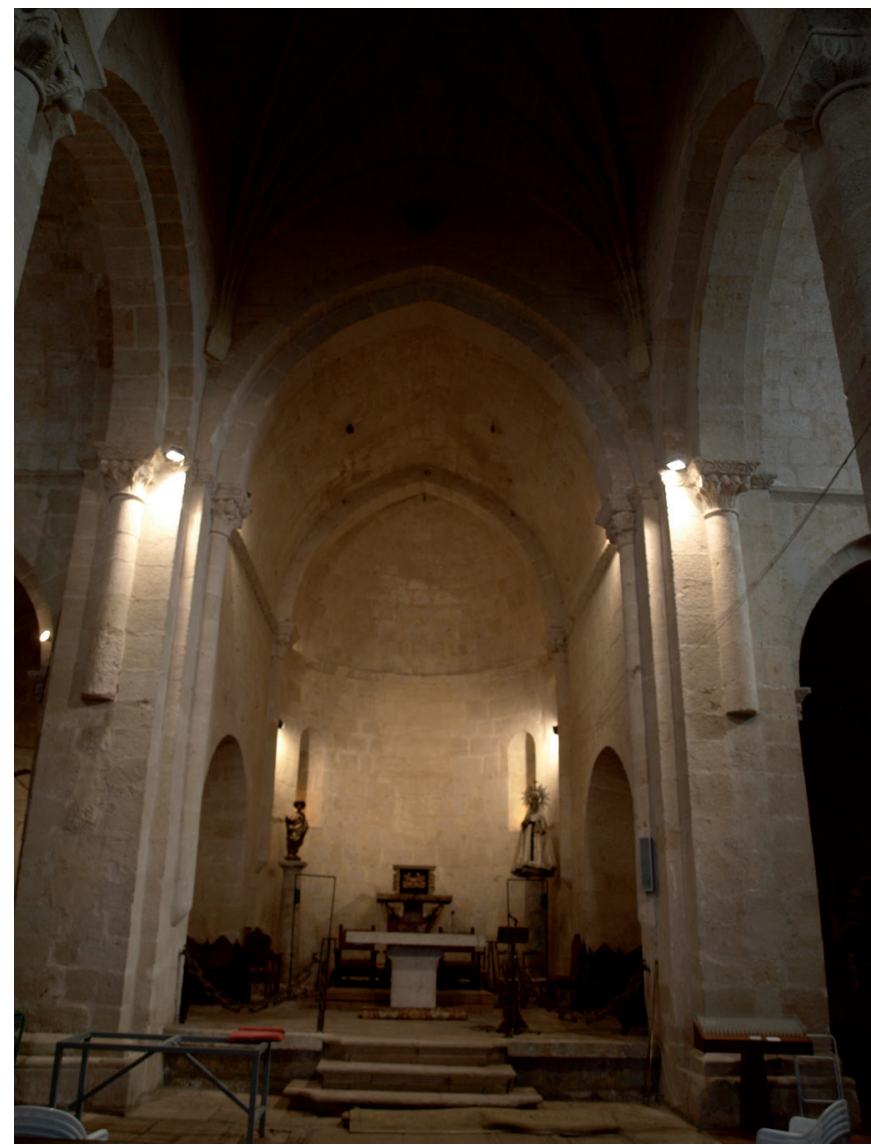

Fig. 8. El ábside central desde el crucero 


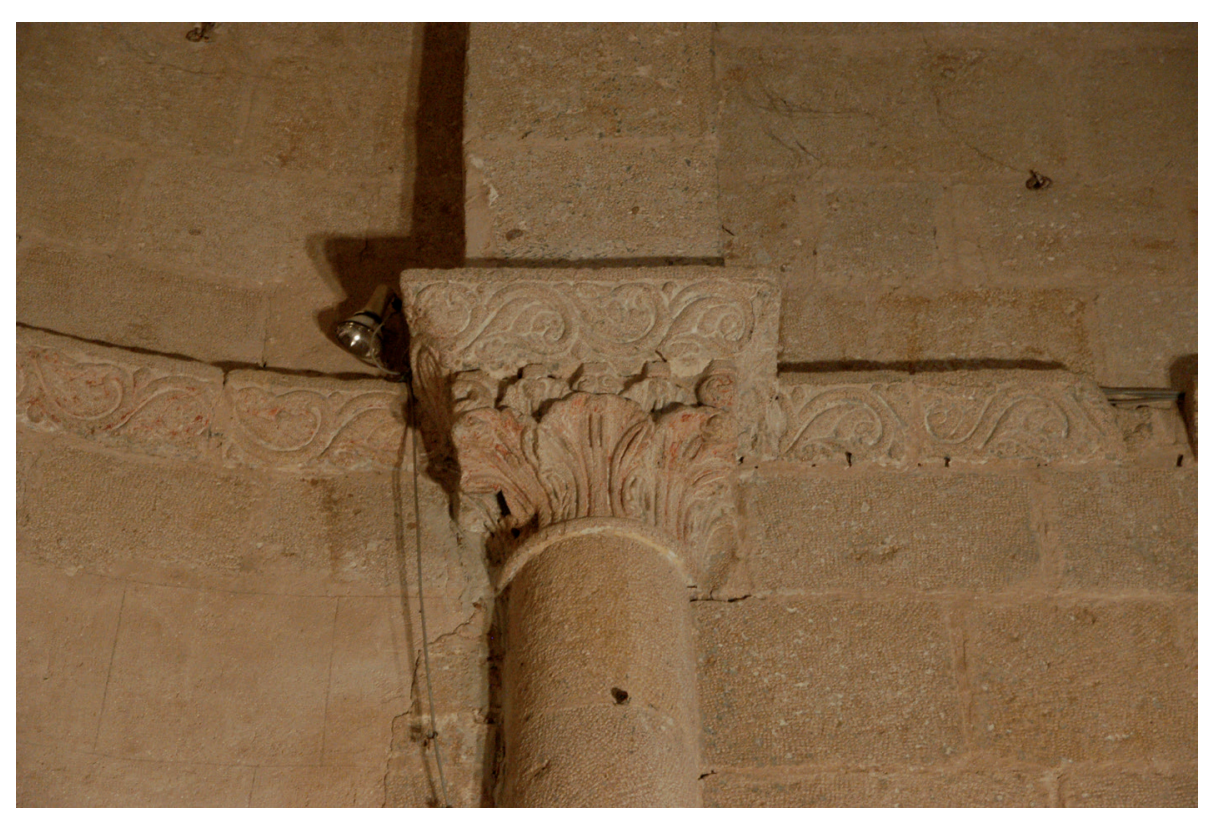

Fig. 9. Detalle de uno de los capiteles de la etapa I. Ábside mayor, muro sur, entre presbiterio y hemiciclo
La combinación de estos datos permite concluir que las bóvedas de cañón apuntado del transepto y gran parte del muro occidental del mismo fueron construidas en la segunda etapa. Asimismo, caso de existir, también la cubierta del crucero románico debió ser, necesariamente, sustituida en época gótica.

La estructura de los espacios que componen las capillas posee la ordenación habitual dentro del estilo románico; arcos de embocadura doblados, tramo recto cubierto con bóveda de cañón apuntada, arco de triunfo sobre columnas y capiteles antecediendo al hemiciclo cubierto con bóveda de horno (Fig. 8). De las ventanas descritas al exterior, no ha sido posible localizar rasgo medieval alguno al haber sido restauradas en época contemporánea (A 153; UE 1093, 1094).

Sí pudimos documentar los elementos ornamentales que recorren las partes altas de esta primera etapa. Son un total de 10 capiteles, 4 ménsulas y varios metros de impostas. En el ábside mayor, la estructura bipartita de su interior sobre arcos fajones ofrece dos parejas de capiteles vegetales con hojas nervadas y potente claroscuro. Sus cimacios e impostas exhiben roleos de grueso tallo y zarcillos (Fig. 9). Guardan una gran similitud, aunque hay ligeras variantes, como la introducción de pequeños motivos animales, con los capiteles orientales sobre los que apean los arcos torales norte y sur del crucero.

Estilo y temática se mantienen en la decoración de los ábsides laterales, si bien la ejecución transmite una menor pericia, puesto que abundan las imprecisiones. Cimacios e impostas muestran círculos entrelazados, en tanto que los capiteles de los arcos de acceso son "fitomórficos", salvo en el sur de la capilla meridional, donde aparecen cuadrúpedos rampantes con el torso girado hasta enfrentar sus cabezas. Al interior de los ábsides, los capiteles del arco que antecede al hemiciclo son aquí estilizadas ménsulas en las que se alternan motivos vegetales, geométricos y, concretamente en el absidiolo sur, figurados de difícil interpretación. Vemos aquí un personaje masculino haciendo sonar un cuerno y otro vestido con ropas talares que levanta la mano derecha en señal de bendición.

Otro elemento a destacar de esta primera fábrica es el constituido por el nicho que, en la actualidad, cobija la pila bautismal en el muro sur. Tal espacio debió de tener, al menos, dos funciones previas; puerta de acceso al templo y, anteriormente, arcosolio con posible carácter funerario (A 101, UE 1154). La presencia de impostas biseladas en todo el intradós de la jamba impide pensar en que fuera originariamente concebido como puerta. $\mathrm{Si}$, como presumimos, su función original fue cobijar un sepulcro, estaríamos ante una prueba evidente del desarrollo de las obras como para que, al menos, alguien decidiera elegir este edificio como lugar para su sepelio. Este monumento fúnebre, sumado a una parte del muro románico fosilizado (hoy enfoscado) sirven como argumento para sostener que la caja del aula, al menos en esta zona meridional, avanzó al menos hasta el límite que hoy fija la puerta neoclásica. Al observar cuidadosamente la jamba occidental de este acceso moderno, los rasgos tipológicos de sus sillares permitieron incluir esta zona dentro de la fábrica medieval. 
Definida la primera etapa, quedan pendientes de resolución dos interrogantes. El primero se refiere al momento inicial de construcción, mientras que una ulterior duda afecta a las razones que justifican la interrupción de este proceso. Para dar respuestas satisfactorias a ambas preguntas, resulta indispensable conocer los detalles de cómo se desarrollaron las tareas en fases sucesivas.

De acuerdo con lo expuesto, el primer impulso constructivo sufrió una alteración antes de proceder con la cubierta del transepto y de lanzar las naves del aula hacia poniente. No hemos documentado ningún indicio que denote una interrupción brusca, y mucho menos una ruina, por lo que resulta lógico pensar que la pausa fue debida a un cambio de obra o un replanteamiento del proyecto inicial. Por otro lado, la siguiente fase presenta una serie de rasgos que la individualizan, si bien combinados con otros ya observados en esta primera etapa. El resultado podría definirse entonces como un segundo empuje constructivo con adaptación parcial al proyecto ya iniciado 6 .

El desarrollo de los trabajos debió ser este: después de la necesaria cimentación, se trazan los ábsides y se delinean los muros perimetrales del transepto; los hemiciclos se levantan hasta la imposta y se procede a cubrir las tres capillas de acuerdo con los parámetros habituales, bóveda de cañón, ligeramente apuntada y de horno en la cuenca absidal. Al mismo tiempo, se dejan preparados los soportes para proceder a la colocación de las bóvedas del transepto, acción que no se concluye en esta etapa. La explicación a tal comportamiento está implícita en la descripción de la siguiente fase.

\section{Etapa II. Cubiertas románicas y cámaras sobre los ábsides laterales.}

Llegados a este punto, podemos decir que el aspecto general del templo ha sido definido. Su parte más importante - capilla mayor y ábsides laterales - está concluida y preparada para acoger celebraciones litúrgicas, por lo que no se puede descartar una consagración en este momento. Transepto y aula, caso de que esta hubiera sido delineada en todos su muros, permanecen sin cubrir. Estas acciones serán llevadas a cabo a lo largo de la etapa que nos ocupa, momento en el que además se materializan algunos rasgos estructurales genuinos del edificio incardinados con su fortalecimiento.

\footnotetext{
${ }^{6}$ Nos referimos, fundamentalmente, a la continuación del husillo en la esquina suroeste del testero sur del transepto así como a la adecuación de las cubiertas pétreas del transepto a los soportes diseñados en la etapa anterior.
}

Es ahora cuando se procede a finalizar la fábrica románica (A 102), tanto en el exterior (UE 1034) como en el interior (UE 1139, 1169). Concluidas estas labores, la parte oriental de la iglesia habría sido completamente abovedada y dotada de un muro de sillería que actúa a modo de parapeto tras el cual se construyeron unas poco comunes cámaras ubicadas por encima de los presbiterios de los ábsides laterales.

Al exterior, esta acción se concreta en la realización de una ancha franja de sillería que recorre todas las partes altas de la cabecera, incluyendo los testeros del transepto y el husillo (UE 1034). El material utilizado así como el aparejo, pese a poseer ciertas concomitancias, se diferencian con claridad de los de la etapa originaria. Se trata de sillares de tamaño medio, en general más pequeños que los de la fábrica primigenia, dispuestos a soga formando hiladas no excesivamente regulares. Sus aristas escantilladas y la multitud de ripios a modo de cuña incitan a pensar en el reempleo de algunos de ellos. Al contrario que en la etapa anterior, aquí las marcas de cantero son prácticamente inexistentes y, salvo la ventana de medio punto en el alzado sur del transepto, no contamos con elementos tipologizables o encuadrables dentro de un estilo predefinido. Utilizando estos discriminantes es posible definir con cierta precisión los límites de esta fase, así como describir los elementos principales que la forman.

El enjarje de la parte superior del husillo con el resto de la fábrica, demuestra que la escalera proyectada en la etapa anterior fue continuada ahora, si cabe con justificado uso puesto que sirve de acceso al complejo oriental de bajocubierta. El muro se prolonga por el testero meridional del transepto y gira en diagonal sobre el presbiterio del ábside sur hasta encontrarse con un lienzo similar que procede del lateral norte de la iglesia. En planta se aprecia cómo se genera una especie de proa que protege un amplio espacio interior, en el que se sitúan sendas cámaras cuya existencia, al exterior, se delata por la presencia de pequeñas aspilleras (Fig. 10). Se trata de un espacio semioculto que, por el momento, denominaremos cámaras suprabsidales?

Al igual que vimos en la anterior fase, también esta tiene su correlato en la zona oriental del interior del

\footnotetext{
Hemos considerado que la sobrecarga que esta obra supone para los muros de la fase románica pudo acarrear la aparición de fisuras en algunos sillares del exterior, sobre todo en las zonas bajas, de la primera etapa (A 130, UE 1033). Es posible que tales fracturas se deban a apoyos diferenciales que sufren los extremos del sillar como zonas más débiles, máxime en éstos que poseen una estereotomía claramente curva.
} 


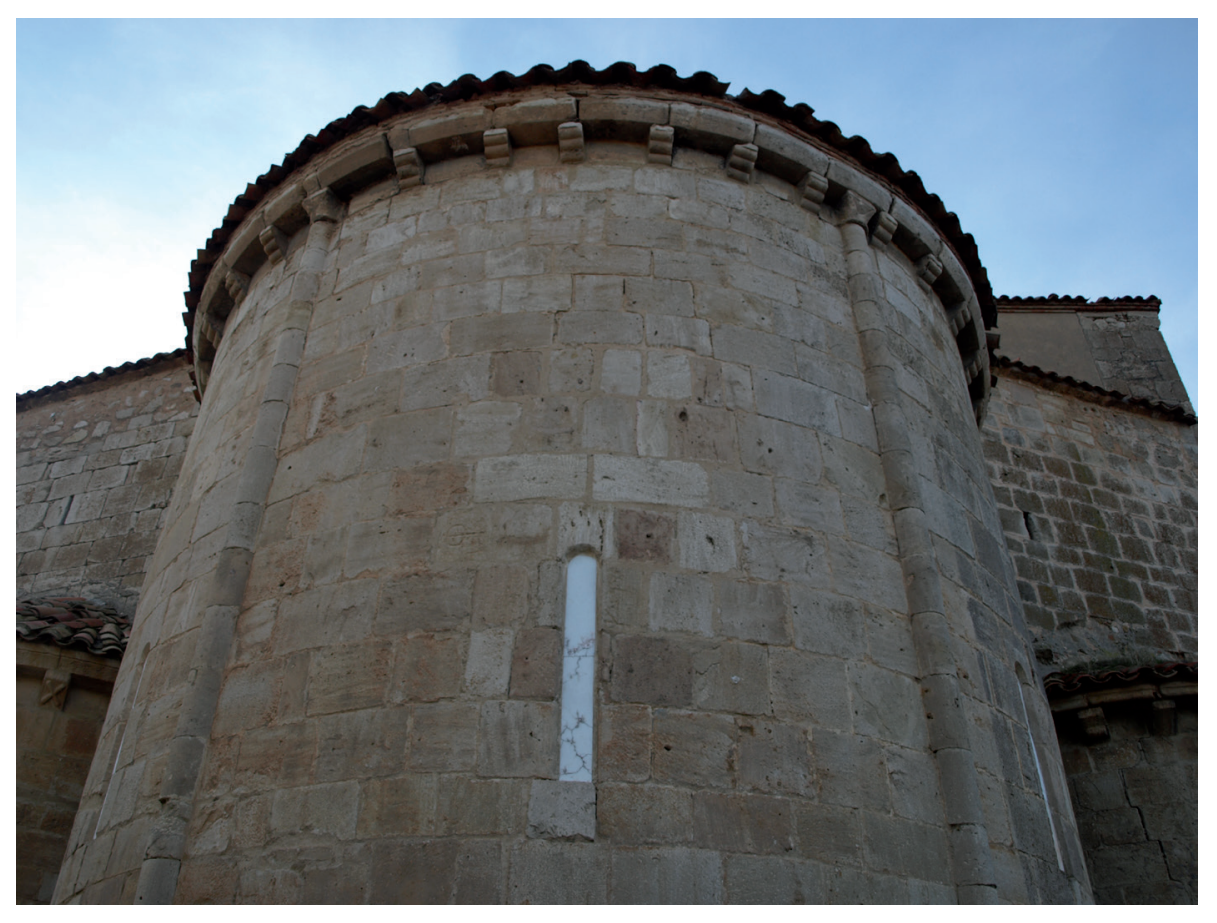

Fig. 10. Ábside principal. Nótese cómo los muros sobre los ábsides laterales que cobijan las cámaras suprabsidales se proyectan en ángulo templo. Es ahora cuando se concluyen las partes altas, incluyendo bóvedas del transepto, arcos y capiteles del muro occidental de dicha nave transversal (UE 1139). Aquí, pese al irritante abujardado de los paramentos, la diferente tipología de la fábrica de esta segunda etapa pudo corroborarse mediante la documentación de evidentes cambios de plano en ciertos paños de los muros de sillería.

Utilizando esta estrategia, pudimos concluir que los capiteles e impostas situados por encima de los mencionados cambios de plano, en el alzado occidental del transepto, poseían características que los diferenciaban de sus homónimos en el muro de enfrente. Por tanto, esta fase cuenta entre los miembros de su cuadrilla a canteros que labran y ubican piezas decoradas. Hay una cierta similitud entre los elementos ornamentados de esta y la anterior etapa, lo que invita a pensar en la utilización de material conservado y puesto en fábrica en este momento ${ }^{8}$. Sin embargo, es ahora cuando se utiliza por primera vez la tipología de imposta "anacelada" sin ornamentación, detalle que ayuda a definir las superficie correspondiente a este momento constructivo. En cualquier caso, la suma de estos datos arroja una información muy jugosa en lo referido a la forma en la que hemos de imbricar dichas etapas en la secuencia evolutiva de la obra, permitiéndonos proponer un replanteamiento de la misma más que una interrupción.

De la información correspondiente a la etapa primera deducíamos que tal vez ya se pudo construir el perímetro del aula. En esta fase se completan los pilares compuestos del primer tramo y sobre ellos apea la bóveda apuntada del transepto, por lo que hemos de suponer que estaban proyectadas las cubiertas de las naves, al menos en la zona más próxima al crucero. Esta conclusión depende en gran medida de la interpretación que efectuamos de las huellas verticales dejadas por los muros laterales del aula (A 103), hoy visibles en el alzado occidental del transepto (UE 1059, 1077). Estos indicios permiten suponer la existencia de un muro perpendicular - posteriormente desmontado y del que desconocemos su desarrollo longitudinal - de mayor altura que los actuales que equivaldría al cierre de la caja del aula de época románica y que sería coetáneo al transepto.

Sin duda, el aspecto más llamativo en este momento de la fábrica es la realización de, al menos una, cámara abovedada sobre la capilla lateral norte (UE 1169), que incluiría, previsiblemente, una similar en el lado opuesto ${ }^{9}$ (Fig. 11). Para acceder a ella, en la

\footnotetext{
8 Ciertos desajustes, especialmente visibles en los capiteles de los arcos
fajones del primer tramo de las naves laterales, podrían venir a confirmar

8 Ciertos desajustes, especialmente visibles en los capiteles de los arcos
fajones del primer tramo de las naves laterales, podrían venir a confirmar esta idea.
}

\footnotetext{
$9 \mathrm{Su}$ existencia viene justificada por la presencia de una pequeña ventana sobre el tramo recto del ábside meridional, si bien no se podrá confirmar tal presunción hasta que se proceda a una excavación en esta zona.
} 


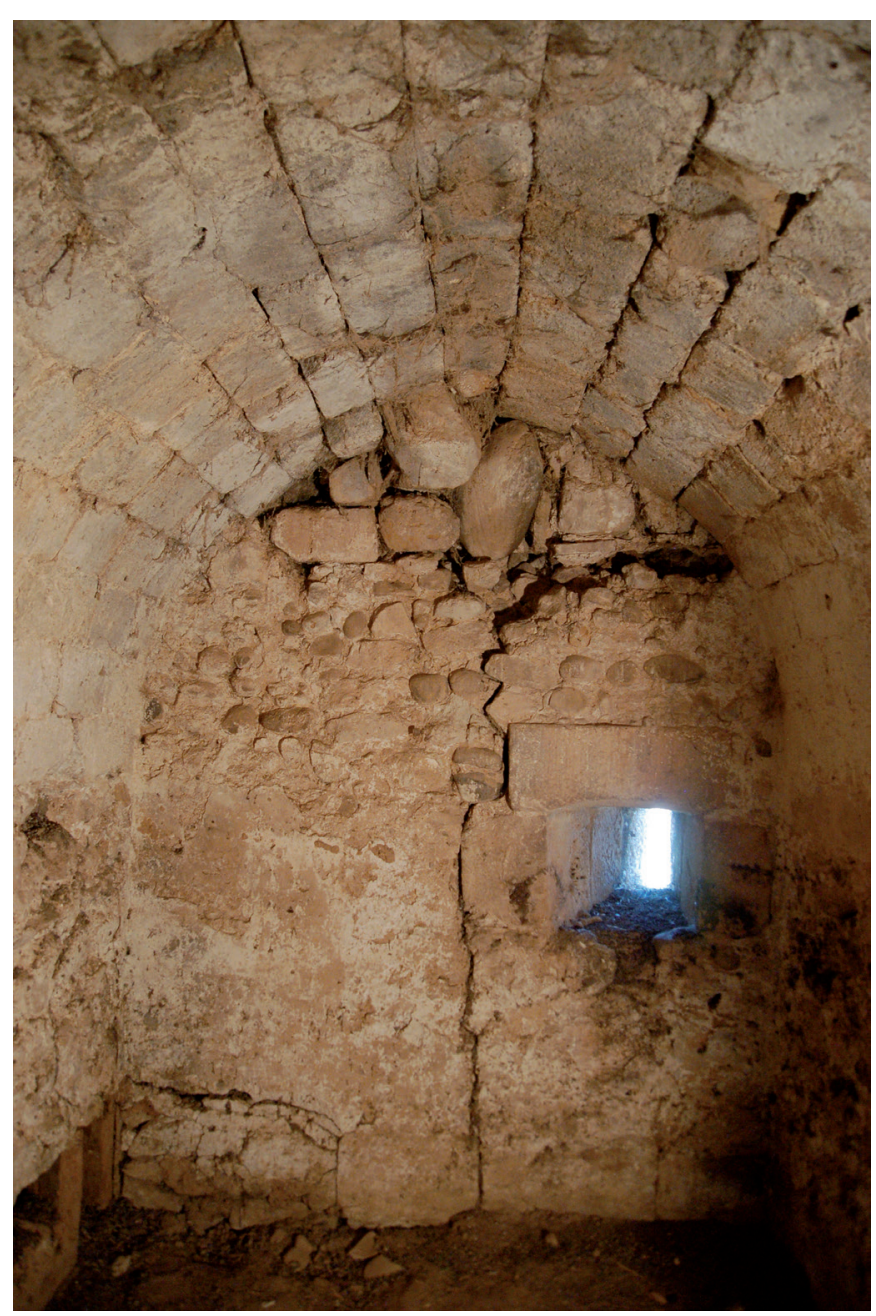

Fig. 11. Interior de la cámara suprabsidal norte

actualidad, se ha de alcanzar el bajocubierta ascendiendo por la escalera de caracol del husillo del brazo sur del transepto. Desde allí es preciso recorrer toda la cabecera hasta llegar a la escalera de dos tramos, con caja de sillería, que permite acceder al interior del edículo. Se trata de una estancia rectangular $(2 \times 3,30 \mathrm{~m}$ aproximadamente) abovedada, dispuesta oblicuamente en relación al eje del ábside norte sobre el que se emplaza, adaptándose al paño recrecido en la cabecera (UE 1034), siendo este uno de los argumentos básicos para considerarlos coetáneos.

No estamos en disposición de garantizar que el actual nivel de uso al interior con un pavimento de tierra batida sea el original. A partir de dicha cota arranca una hilada de sillería de tamaño medio con marcas de cantero (cruces mayoritariamente), de fino trazo. Sobre esta se asienta un banco de cantos rodados y mampuestos pequeños trabados con mortero que sirve, a su vez, de asiento para la bóveda de medio cañón construida con sillares. Posee dos ventanas, una hacia el norte y otra hacia el este, simples aspilleras al exterior pero abocinadas notablemente en su desarrollo interno hasta formar un arco rebajado, cuya tipología remite sin problemas a tiempos medievales.

Completada esta segunda etapa, podemos garantizar la elevación y cubierta de toda la zona oriental del edificio, incluido el transepto. Menor definición posee la información con la que contamos para conocer el estado de la construcción del extremo este del aula. Con seguridad estaban preparados los pilares para recibir las cubiertas de los tramos más cercanos a la cabecera, si bien no podemos garantizar que las bóvedas llegaran a proyectarse. Carecemos de datos acerca de la solución originaria para la cubierta del crucero, puesto que este espacio está actualmente ocupado por un cimborrio gótico con bóvedas de terceletes remontado en el siglo XIX (Fig. 12).

\section{Etapa III. Cierre occidental del transepto y comienzo del aula}

No sin dificultad, la construcción pudo avanzar hacia los pies de forma aparentemente ininterrumpida, aunque mostrando importantes correcciones con respecto a lo atisbado en las etapas anteriores. Pese a las dificultades de observación que supone la presencia de encalados interiores, pudimos identificar los restos de las arquerías medievales (A 105) y el cierre oeste del transepto (A 104), acciones ambas que ponen de manifiesto la finalización de los trabajos en esta zona del templo.

La pauta que seguirá a partir de este momento la fábrica denota una evidente pauperización de los medios con los que se contaba. Esta circunstancia se aprecia con claridad en el alzado de poniente de la nave que actúa de transepto, todavía hoy visible a ambos lados de la nave central (UE 1057, 1076, 1078). Se trata de un muro de mampostería, ladrillo y mortero de cal de aparejo irregular, que cubre la superficie sin formar hiladas o bancos. A través de esta operación se desbarata parcialmente lo proyectado en la etapa anterior, donde los muros perimetrales del aula eran más elevados. Se rebaja así considerablemente la altura de las naves laterales, tal vez con la idea de adecuarlas a la tipología de las cubiertas que, por fin, podemos asegurar existieron en los primeros tramos del aula.

Resulta muy interesante el haber podido constatar que es en este periodo cuando se procede a lanzar los arcos formeros de separación (A 105). Los restos de 


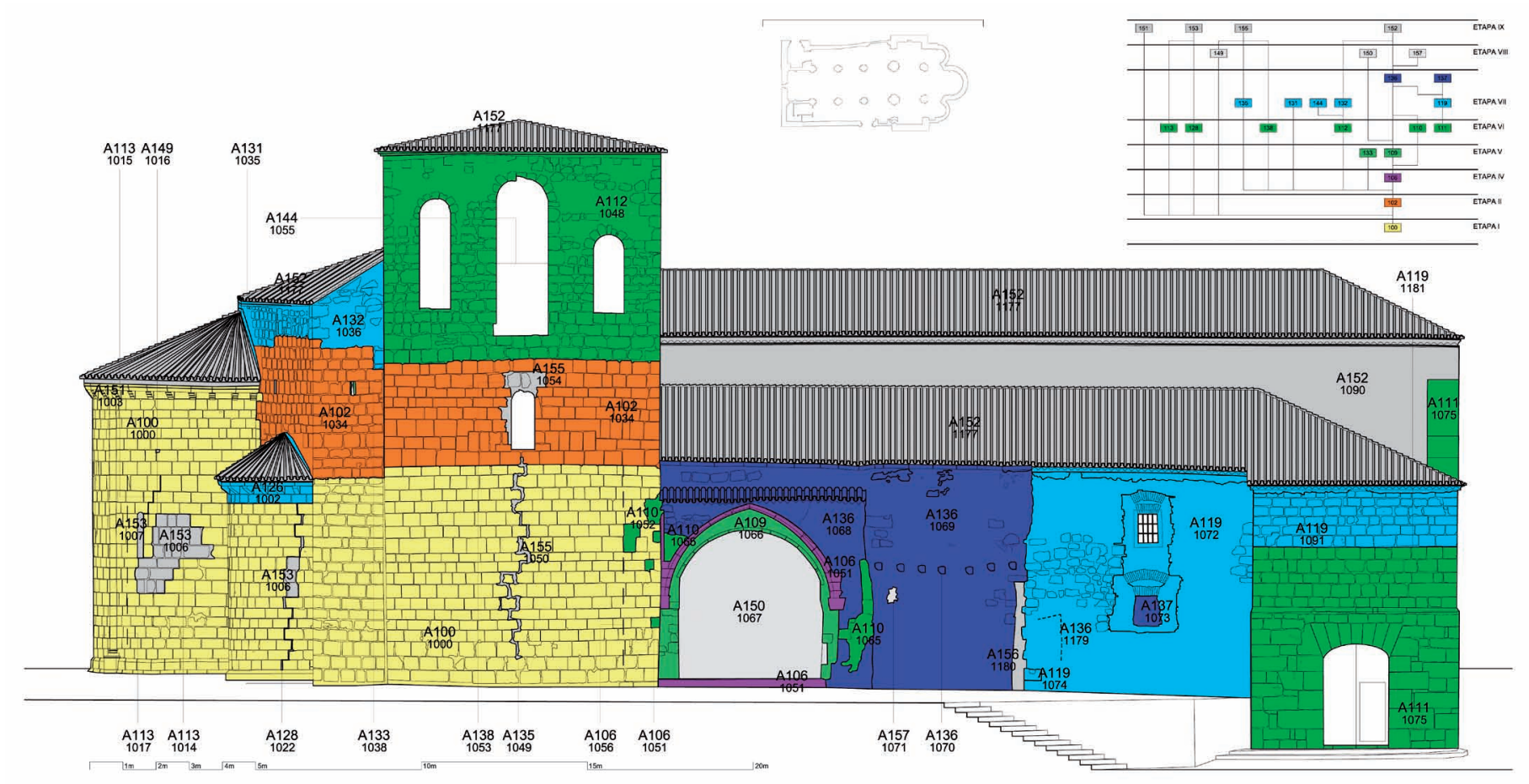

Fig. 12. Alzado norte. Exterior

esta arquería primigenia son visibles todavía al exterior de la nave central, en su lado meridional (UE 1085), y también al interior, esta vez en la cara sur de la arquería norte (UE1164) y únicamente adivinando su perfil bajo los enlucidos posteriores ${ }^{10}$ (Fig. 13). Si tomamos el primero como referencia, podemos concluir que se trató de arcos apuntados realizados en piedra y cuya anchura es sustancialmente más amplia que cualquiera de los descritos hasta ahora (por ejemplo, los torales del crucero o el de triunfo). Al proyectar su previsible luz, se observa cómo estos apoyarían hacia oriente sobre los pilares del transepto, mientras al oeste irían a descansar en otros, actualmente desaparecidos, que se situarían aproximadamente en el lugar que hoy ocupa el tercero de los de época moderna. Por lo tanto, se podría considerar que cada tramo de la nave medieval correspondería aproximadamente a dos de los actuales. La clave de estos arcos se sitúa en una cota inferior a la de la cumbre del transepto, lo que induce a pensar

\footnotetext{
10 El alzado norte de la arquería septentrional pudo ser documentado en el espacio bajocubierta por el equipo que llevó a cabo el levantamiento planimétrico.
}

que respondan a proyectos distintos, si bien ambos situados dentro de un horizonte cultural y artístico indudablemente medieval. Al rebaje sustancial de la altura del aula hemos de sumarle la inferior calidad de los materiales utilizados puesto que un documento del año 1781 nos revela que la cubierta de este espacio, suponemos que sobre los arcos apuntados, fue realizada en madera ${ }^{11}$.

Nos situaríamos aquí frente a la que debió ser la última etapa del periodo románico, si bien conjeturamos que ya dentro de las cronologías habitualmente manejadas para el estilo gótico. Un proceso constructivo que se nos ha revelado lento y caracterizado por cambios de proyecto, tal vez relacionados con el intento de fortificar la zona hacia levante. Ya concluido, documentamos un tramo destinado a los fieles en el que las poderosas cubiertas pétreas dieron paso aquí a otras realizadas en madera, evidenciándose así un más que posible descenso en la disponibilidad de recursos destinados a la construcción del edificio.

\footnotetext{
11 Archivo Diocesano de Osma-Soria (a partir de ahora ADO-S), Libro 38/34, s.f., r-r-v-r-v, mayo, 25.
} 


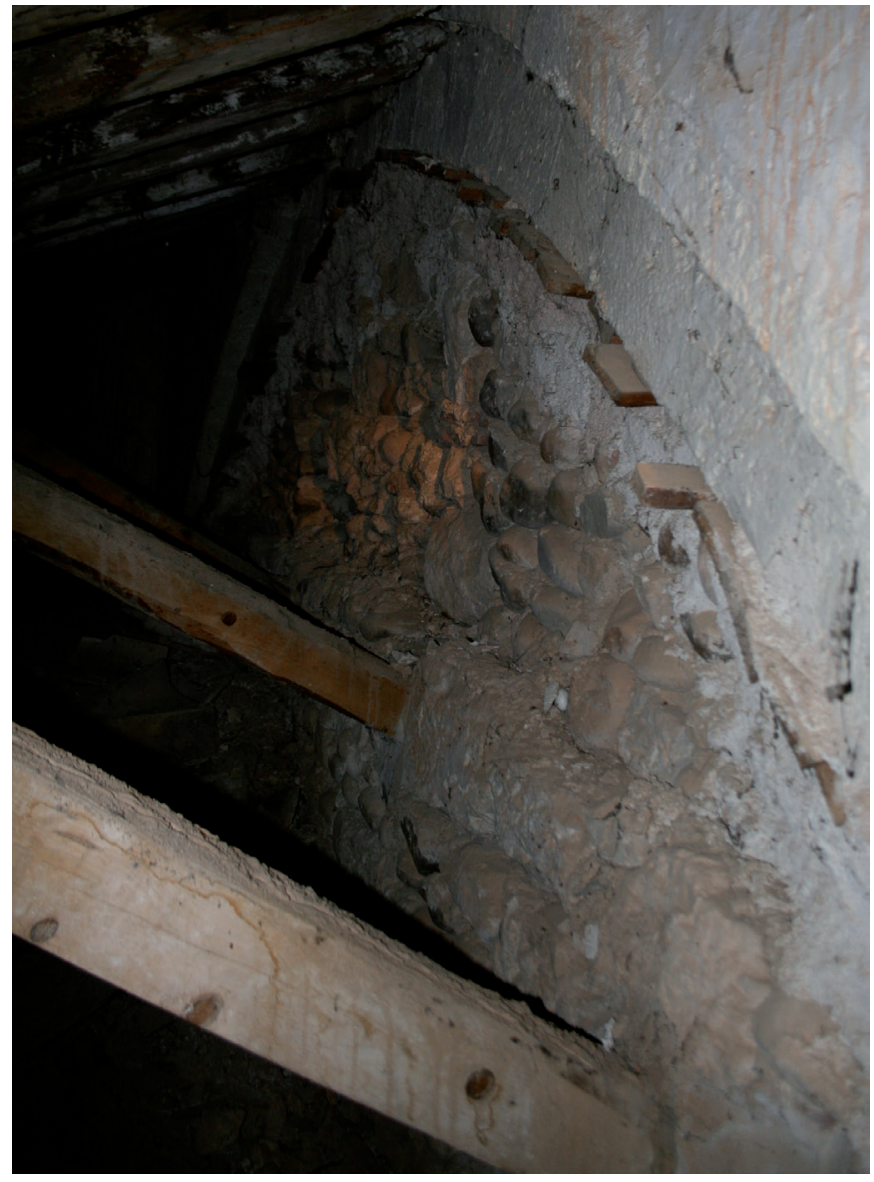

Fig. 13. Arco medieval en piedra embutido en el muro norte de la nave central. Etapa III

\section{«Más parece una fortaleza que un templo»}

No contamos con argumentos estratigráficos, tipológicos o documentales que permitan rebatir la cronología tardorrománica para el inicio de las obras que, en líneas generales, ha sido consensuada por la historiografía. Parece razonable mantener como referencia un horizonte de finales del siglo XII. En cierto modo, el contexto histórico de la villa aconseja utilizar una fecha tardía dentro del estilo románico, si bien no tanto en el contexto soriano. El asentamiento definitivo tras la pacificación de la zona se produjo en tiempos del dominio aragonés de Alfonso I y su inclusión en los límites del obispado de Tarazona (Rodríguez 2002: 129). Sería a partir de entonces cuando surjan nuevas parroquias extramuros del recinto militar que, con el correr del tiempo, fueron incluidas dentro de un segundo cinturón amurallado ${ }^{12}$.

\footnotetext{
12 La historia medieval de Almazán está estrechamente ligada a la evolución de sus murallas, parte de las cuales se mantienen todavía en pie y que llegaron a encerrar, en el momento de máxima extensión, un recinto que incluía este cerro meridional y la parte de la villa hasta su encuentro con el Duero. La tradición
}

Resulta incuestionable que al finalizar estas tres etapas la zona oriental de la fábrica poseía el aspecto abaluartado que da pie a los eruditos decimonónicos a la afirmación que abre este epígrafe. Parece claro que en el ánimo de los primeros constructores se encontraba proyectar un piso superior con acceso desde una escalera de caracol en el extremo sur del transepto. Así al menos parece desprenderse del hecho de que el husillo que alberga este elemento se contemplara en la fase inicial. Ahora bien, no sabemos si tal espacio incluía, inicialmente, la construcción de la cámara (previsiblemente «cámaras») sobre el tramo recto del ábside norte. No podemos pronunciarnos de manera tajante al respecto ya que, este replanteamiento no provocó alteraciones profundas en la fábrica primitiva, si exceptuamos algunas insignificantes grietas y desperfectos mínimos en ciertos sillares de las partes bajas de la cabecera.

Sea como fuere, esta acción está directamente ligada a la cubierta del monumental transepto al que se abren los tres ábsides en batería, así como del desaparecido cimborrio en el crucero. En esta actividad sí encontramos referentes tipológicos y estilísticos que nos permiten situarla en una cronología románica. Bóveda de cañón, impostas y capiteles deben enmarcarse sin duda dentro de este léxico tecnológico y ornamental.

Muy diferente resulta conjeturar acerca de la función para la que fueron instaladas estas cámaras ${ }^{13}$. Que los templos medievales cobraron papeles protagónicos

las adjudica un origen árabe, cuando no romano (Madoz 1845: 81). Sin embargo el conjunto de lo conservado pertenece a los siglos XI-XIII (Ortego 1973: 51) y, en sucesivas etapas, amplía el recinto primigenio de El Cinto (Márquez 1987: 39) donde se situaba el castillo. Esta zona, junto a la que se sitúa nuestra iglesia, perdería parte de su importancia en el siglo XV, coincidiendo con la construcción del palacio de los Hurtado de Mendoza junto al río (Rodríguez 2002: 131). En cualquier caso, es posible que, desde el siglo XIII, las murallas cumplieran un cometido jurídico a la par que defensivo — de ahí su mantenimiento- , cercando la superficie comercial de la villa (Muñoz 1990: 92). Una parte importante de las defensas fueron demolidas durante la francesada, una orden dada por el general español Durán, tratando de evitar que el enemigo las utilizara en favor propio (Ortego 1973: 53).

13 En un trabajo reciente, Boto (2008), tras analizar de forma individual algunos de los ejemplos más monumentales de estas cámaras elevadas sobre las zonas orientales de ciertos edificios románicos — Sant Pere de Galligans y Santa María en Santa Cruz de la Serós, entre otros-, concluye acerca de la necesaria variedad funcional de tales ámbitos. Con estas dos mencionadas, las cámaras de Campanario comparten características como lo intrincado de su acceso y una cierta concomitancia técnica, que no morfológica, por cuanto también las nuestras están realizadas con sillería de características románicas. Difieren, en cambio, en lo referido a la comunicación con los espacios privilegiados para el culto y, mucho más aun, en la inexistencia de espacios absidales que pudieran desvelar la presencia de altares con carácter litúrgico. Al contrario que en el caso gerundense y oscense, en los que parece confirmarse su raíz monacal, carecemos de cualquier referencia que, ni tan siquiera, nos permita precisar acerca de la naturaleza de quienes mandaron realizar o utilizaron dichos espacios. 
en funciones que van más allá de las meramente congregacionales es una circunstancia que hemos de asumir a la luz de documentos y evidencias materiales. Pese a la generalizada ausencia de referencias documentales, entre otras misiones, la iglesia, como edificio, debió convertirse en espacio de almacenamiento y también en lugar fuerte dentro de una villa medieval (Nuño 2002: 129 y 131; Nuño 2008: 153). En el caso que nos ocupa, las estancias sobre los ábsides disponían únicamente de un intrincado acceso que dificulta la subida de objetos de gran volumen o peso, por lo que hipotéticamente podríamos descartar su uso como depósitos. Esta función, no obstante, no invalida que aquí se guardaran objetos de reducido tamaño y, previsiblemente, de cierto valor ${ }^{14}$.

Más sencillo resulta imaginar una estructura fortificada, compuesta de sólidos sillares, con extrema dificultad para acceder a ella, circunstancia que redunda en su carácter defensivo. Podemos, incluso, redibujar los remates de los muros si eliminamos la cubierta leñosa actual, lo que liberaría por completo esta zona y la dejaría abierta a modo de gran terraza desde la cual apostarse, vigilar y defenderse. Por otro lado, tenemos la certeza de que los muros perimetrales del aula alcanzan en este momento una altura desorbitada en relación con la de las naves laterales, marcada por los arcos que abren al transepto. El esquema resultante, de acuerdo con este desarrollo hipotético del alzado del aula, mostraría un espacio sobre dichas naves que quedaría oculto tras los paramentos norte y sur. Tal vez este desnivel fuera proyectado como bajocubierta, aunque también podría conformar un segundo piso en todo el perímetro del edificio. Los acontecimientos violentos documentados en Almazán, desde finales del siglo XII, en nada contradicen esta interpretación, si bien hemos de advertir sobre su carácter hipotético ${ }^{15}$. Pese a que la consolidación de la red parroquial puede ser interpretada como indicio de estabilidad política, social y

\footnotetext{
14 Como sucede en los llamados «tesoros» que son espacios destinados a custodiar los objetos de valor (muy especialmente los documentos de propiedad) en algunos monasterios cistercienses como el cercano de Santa María de Huerta o el de Valbuena (Martín 2008: 188).

15 Las remodelaciones pluriseculares a las que se han visto sometidos muchos templos medievales ha provocado que dicha función pueda ser deducida a través de elementos individuales, tales como husillos o pequeños vanos (Bango 1997-1998: 69). De acuerdo con los estudios de Dimanuel, tal vez el rasgo más identificable de estas iglesias fortificadas son las saeteras, bien como aperturas para el tiro, bien como simples respiraderos. Mucho más interesante es el dato que esta autora nos proporciona en cuanto a la costumbre conocida en la documentación medieval francesa como salles d'armes (Dimanuel 2006: 91 y 93, n. 34) por cuanto se trata de recrecer los muros de la cabecera para establecer espacios protegidos con diferentes fines, entre ellos la concentración de tropas, comunicados mediante pasos de ronda (Nuño 2008: 154-155).
}

económica, en el caso que nos ocupa, las disputas episcopales de Osma y Sigüenza por incluir la villa dentro de los límites diocesanos debió provocar no pocos conflictos (Ortego 1973: 12). No en vano, las tropas de Alfonso VII llegaron a ocupar algunas zonas para hacer cumplir lo dictado por el papado y sólo en 1165 es restituida al obispado seguntino (Márquez 1987: 37).

$\mathrm{Su}$ condición fronteriza entre castellanoleoneses y aragoneses también provocó situaciones de tensión durante la plena y la baja Edad Media. Así ocurrirá durante el conflicto sucesorio acaecido a la muerte de Alfonso X. El rey aragonés Alfonso III, alineado en el bando de los infantes de la Cerda que reclaman el trono castellano contra su tío Sancho IV, se apostó con sus tropas frente a Almazán, que tomará por la fuerza en 1290 pasando a ser temporalmente corte del infante rebelde don Alfonso (Madoz 1845: 54; Ortego 1973: 13). No será hasta la regencia de María de Molina, esposa de Sancho el Bravo, cuando la villa pase de nuevo a manos castellanas para ser gobernada por el hijo de ambos, futuro Fernando IV. Pese a todo, todavía a comienzos del siglo XIV quedan algunos rescoldos de oposición que fueron descritos de manera muy gráfica por la reina viuda a su vástago, pues habla de «algunos caballeros e malfechores que tenían casas fuertes desde donde hacía mucho mal» (Ortego 1973: 14). Entre 1356 y 1369 Almazán volvió a convertirse en base para las operaciones militares de las tropas castellanas que desde la frontera amenazaron territorio aragonés durante la llamada Guerra de los dos Pedros (López de Ayala 1991: 199-201).

Si esta centuria se desarrolló de manera agitada, hemos de pensar que avanzado el tiempo la situación no habría mejorado sustancialmente. Un tiempo de crisis poblacional y de contracción económica que ha quedado perfectamente reflejado en una carta de privilegios dada por Enrique III, con fecha de 20 de febrero de 1392, en la que se dice «que para recompensar los muchos servicios que la villa de Almazán hizo a sus mayores y a él mismo, y porque la villa y arrabal eran pobres y estaban yermas y despobladas, las libera de todo pecho, servicio y fonsadera...» (Ortego 1973: 17). También durante el reinado de Juan II, a comienzos del XV tenemos noticias sobre nuevas tensiones entre Castilla y Aragón. En el año 1429, un ejército compuesto por más de dos mil hombres dirigido por don Álvaro de Luna, condestable de Castilla, se guareció en los muros de Almazán a la espera de entablar batalla con las tropas de Alfonso V de Aragón que habían tomado el monasterio de Santa María de Huerta (Huerto y Frías 1991: 11). 
Si bien no referido a la iglesia que nos ocupa, el agitado discurrir por la historia adnamantina no desentona con las características fundamentales de la dilatada construcción románica; replanteada como si de una fortaleza se tratara y concluida apresuradamente y con un descenso de calidad notable debido, en nuestra opinión, a la más que probable merma en los recursos destinados a su finalización.

\section{4.- Usos, reformas, reparaciones y restauraciones}

El sufrido deambular de la iglesia por la cronología plenomedieval es solamente la antesala de una agitada vida que se prolonga hasta la actualidad. Es evidente que no todas las etapas que surcan esta trayectoria gozan de la importancia de las hasta aquí expuestas. La calidad de la información obtenida tras nuestro análisis presenta altibajos que guardan relación con la posibilidad o no de acceso a la estratigrafía muraría. Sin embargo, la combinación con los datos extraídos de la documentación conservada ha permitido presentar interesantes novedades referidas a los restos de época gótica así como a los avatares de la fábrica durante la Guerra de la Independencia.

\section{Etapa IV. El siglo XV y las reformas góticas de carácter funerario}

A finales de la Edad Media, al menos el transepto y el tramo más inmediato al mismo, acogieron monumentos funerarios tan representativos de la piedad del momento ${ }^{16}$. El impulso experimentado por esta villa en el tránsito a la Edad Moderna, su eventual capitalidad y el enriquecimiento consiguiente, pudieron contribuir a la realización de estos espacios ${ }^{17}$. Fue entonces cuando

\footnotetext{
16 El lector habrá reparado en que situamos en esta fase una serie de grafitos que surcan los muros exteriores de la cabecera (A 127), incluida la inscripción funeraria situada en la esquina SE del transepto y que fue transcrita por Rodríguez (2002: 154) como HIC: TV / MULO: EST / [¿me?]: FE[c]I[t] / ERA M: CC [...]/ VXOR / SVA : BRV[¿nil?] / DA y situada a finales del siglo XII. Como actividad que agrupa unidades similares pero con diferente cronología toma como límite ante quem el de la más moderna. Con esto no queremos decir que nos mostremos en contra de dicha datación sino que, como conjunto, todos estos grafitis poseen como límite post quem la construcción de la parte oriental del templo. Dicho de otro modo, la inscripción, además de datarse a sí misma, tan sólo sirve para situar el techo cronológico de la zona del edificio en la que fue tallada.

17 De recuerdo más placentero es para Almazán el reinado de los Reyes Católicos, dado que el lugar fue frecuentado hasta en diecisiete ocasiones por los monarcas entre 1474 y 1515 (Ortego 1973: 20), ofreciéndose como aposento regio el palacio de Antonio Hurtado de Mendoza, conde de Monteagudo y señor de Almazán. La influencia de este importante linaje mobiliario, además de servir como polo de atracción a la real pareja, supuso un aumento considerable en la relevancia de esta ciudad que se convertirá en el núcleo urbano más importante de la Extremadura soriana tras Soria y Ágreda. Se llega incluso a considerar que durante aproximadamente diez meses del año 1496 estuvo
}

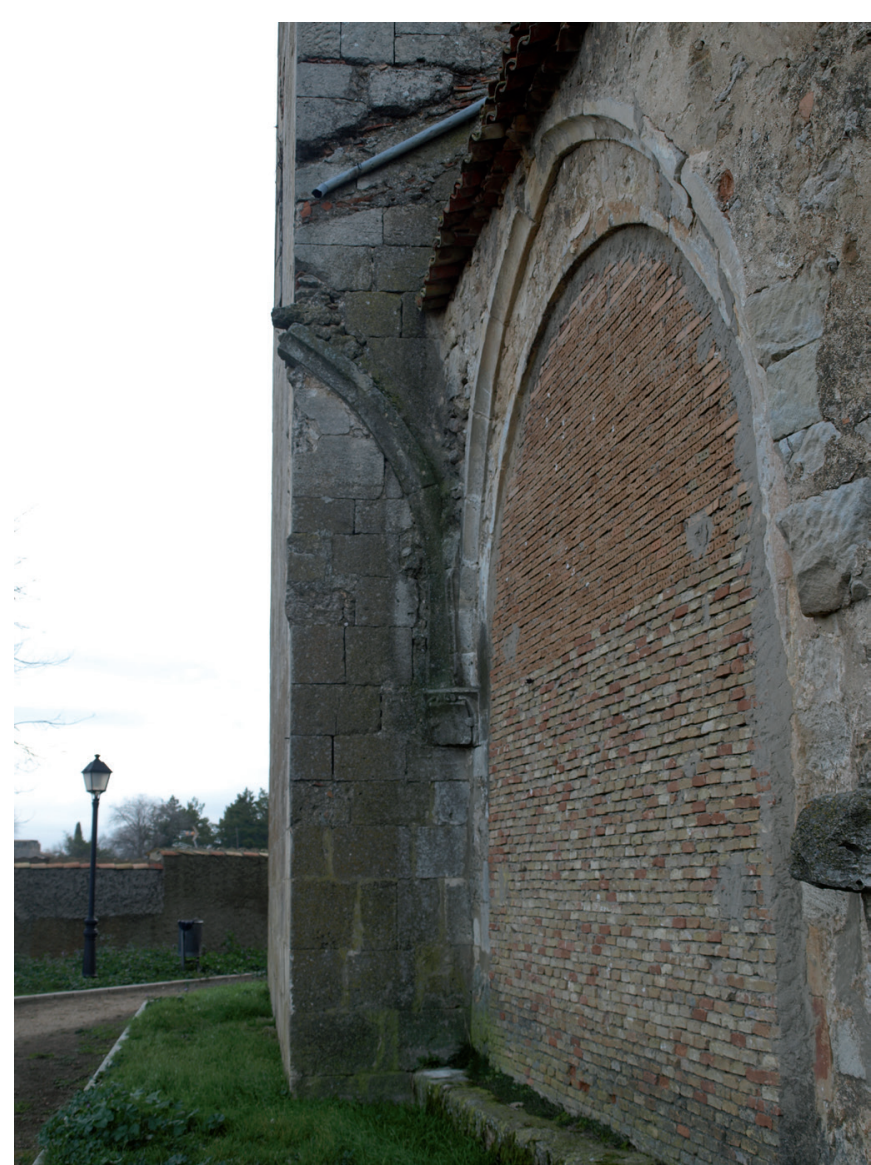

Fig. 14. Restos del desmonte de la capilla gótica en el costado septentrional

se construyó, adosada al muro norte del edificio, la capilla de los Laynez (A 106), que sería desmontada en el siglo XVIII ${ }^{18}$, pero de la que conservamos importantes restos, como el arranque de los nervios de la cubierta de crucería, las molduras del arco apuntado de acceso y el umbral original (UE 1051. Fig. 14). Nada, sin embargo,

instalada la corte en la villa (Tudela 1962: 169). El esplendor político debió de tener, además, una contrapartida artística, puesto que se ha podido documentar la llegada de numerosos artesanos atraídos por la corte, cuando no formando parte de ella. De acuerdo con los inventarios, la reina llevaba consigo a pintores e iluminadores, plateros y tapiceros, y es posible que muchos recibieran encargos de las más importantes casas nobiliarias de Almazán así como de las instituciones eclesiásticas (Diago 1993: 258). Por lo tanto, para cuando los Reyes Católicos establecen su corte transitoria en Almazán, y cuando por sus calles pasean nobles de importancia como los Hurtado de Mendoza o los Laynez, la iglesia de Ntra. Sra. de Campanario debía de ofrecer un aspecto acabado. Así, al menos, hemos de pensar a la luz de su elección como lugar de reposo eterno para algunos de los personajes más notables de la villa

18 Resulta sumamente interesante la información proporcionada por algunos documentos de comienzos del siglo XVI respecto a la presencia de familias de conversos viviendo en las proximidades de la iglesia, entre ellas la de Diego Laynes que «biue en la casa donde solía byuir quando judío» (Carrete y Fraile 1987: 132). En hasta cuatro referencias del año 1505 de las recopiladas en esta obra se menciona a la iglesia del «Canpanario». 
permite adivinar la distribución interna y solamente la excavación del área ocupada por esta podrá contribuir a aumentar nuestro conocimiento al respecto.

Por tipología, función y por situarse cortando la fábrica originaria, situamos en este momento la apertura de un lucillo sepulcral en el interior del brazo meridional del transepto (A 117, UE 1183). Hoy, sin embargo, se muestra cegado y cubierto por la restauración contemporánea. En una línea similar situamos la reforma del único enterramiento privilegiado documentado de época románica. El arcosolio del primer tramo del muro de la nave lateral sur es modificado en su perfil apuntado para convertirlo en medio punto sobre tabiques o rejas no conservados (A 163, UE 1156).

Debemos puntualizar que, pese a que sus rasgos apuntan a una cronología del gótico avanzado (Martínez 1980: 406), la bóveda estrellada sobre el crucero y bajo la torre-cimborrio fue completamente rehecha en el siglo XIX. Es muy probable que su aspecto originario fuese cercano al que hoy muestra; sin embargo las razones estratigráficas que aseguran su alteración nos hacen ser prudentes a este respecto.

\section{Etapa V. Las primeras intervenciones en la Edad Moderna}

Debido a la gran modificación de las naves que se producirá en la siguiente etapa, solamente estamos en condición de enumerar ciertas reformas modernas en la zona del transepto y de la cabecera. Situamos los límites de esta fase, de manera flexible, entre los siglos XVI y finales del XVIII. Parece que debió de ser durante este largo periodo cuando se adosó una estructura de grandes dimensiones que llegó a ocultar buena parte del exterior del ábside central, del absidiolo sur e, incluso, el testero meridional del transepto (A 114). Pese a haber sido liberada de edificios adosados, quedan huellas de las suturas exteriores así como de los huecos abiertos para comunicar el interior del edificio con las nuevas dependencias. Rozas originadas por la retirada de las cubiertas (UE 1010, 1023 y 1046) y de forjados (UE 1030 y 1031), restos de enlucidos interiores pertenecientes a dichas estancias (UE 1026) y numerosos agujeros restaurados (UE 1009, 1025, 1027 y 1032) son los indicios más evidentes de un uso secular de este espacio, probablemente con función de sacristía ${ }^{19}$. Todavía hemos podido ubicar con precisión la

\footnotetext{
19 De los documentos conservados, la mención más antigua a esta dependencia data de 1659 ( $« 9$ reales de una llave que hizo para la sacristía», ADO-S, Libro 38/33, f. 33r 1659, abril, 5). Sí podemos precisar más el desmonte de los mismos, puesto que contamos con imágenes del Archivo Cabré, del
}

puerta (UE 1029) y la ventana (UE 1030) que comunicaban la capilla sur con este gran edificio.

Al mismo tiempo, se documentan varias intervenciones al interior con el objetivo de adecuar el vetusto templo medieval a las nuevas necesidades litúrgicas propias de la Contrarreforma. Tal vez la más arriesgada sea la que seccionó los muros laterales de la capilla mayor para la apertura de dos grandes arcos de medio punto en esviaje con derrame parcial dirigido hacia la cuenca del ábside (A 107, UE 1103) donde debió de situarse el altar mayor $^{20}$. Se facilitaba así el seguimiento de los oficios desde cualquier punto de las naves.

Esta nueva escenografía fue acompañada de la instalación de elementos mueble como retablos y altares secundarios así como púlpitos ${ }^{21}$. En esta misma línea interpretativa situamos las desaparecidas estructuras en los muros laterales del transepto, cuyas huellas nos permiten concebirlas como tribunas (posiblemente de madera) elevadas. Su función exacta nos es desconocida y creemos que la septentrional pudo servir de acceso directo a la cámara suprabsidal sobre el ábside norte (A 118; UE 1112, 1160, 1144). Para facilitar esta conexión, fue preciso abrir tres puertas que afectaron a la fábrica románica; una en el muro oeste del transepto (UE 1144) y su correspondiente en el lado este (UE 1111), además de otra en el muro norte de la cámara (UE 1173). De confirmarse tal hipótesis permitiría confirmar el uso de esta estancia semioculta durante la Edad Moderna.

Prácticamente nada podemos decir respecto al cuerpo de naves, como veremos profundamente reformado en la siguiente etapa. Todo cuanto nos dice la documentación de momentos anteriores a esta modificación es que poseía un órgano $(1652)^{22}$, las puertas de la iglesia se encontraban a poniente (1659) ${ }^{23}$ y que contaba con un coro, posiblemente en madera $(1692)^{24}$.

\section{Etapa VI. Construcción del aula barroca}

Cuando la Edad Moderna toca a su fin, se emprenden una serie de obras que contribuyen a dotar al edificio con una gran parte de su actual apariencia. La ruina

\footnotetext{
IPCE, tomadas en la década de los 20 del siglo pasado en las que todavía son visibles.

20 En el año de 1652, se encarga al pintor Urbán Manuel de Pedreguera el «dorado y estofado del retablo del altar mayor» (AHDB, 38/33, f. 13r).

21 La primera noticia de púlpitos en la iglesia data, al menos en la documentación conservada, del año 1692 (ADO-S, Libro 38/33, f. 177r 1692, mayo, 8).

22 ADO-S, Libro 38/33, f. 12v 1652, junio, 20

23 ADO-S, Libro 38/33, f. 33r 1659, abril, 5.

24 ADO-S, Libro 38/33, f. 177v 1692, mayo, 8 .
} 
inminente de ciertos espacios aconsejaba actuar de manera inmediata. Por estos motivos, se había llevado a cabo el desmonte controlado de la capilla gótica en el costado septentrional, en aquellas fechas conocida como del Santo Cristo (A 110, UE 1065). La documentación conservada ofrece detalles de una operación que fue llevada a cabo por dos maestros albañiles de la villa en el año $1762^{25}$, quienes procedieron también a la venta de parte de los materiales obtenidos.

No debieron los responsables del templo quedar satisfechos con esta intervención, lo que apenas veinte años después les empujó a acometer la reforma total de buena parte del edificio. El profundo calado de esta actividad ha permitido establecer estratigráficamente unos límites amplios dentro de los cuales se inscribe la construcción del aula y el hastial occidental (coro y puerta de la esquina $\mathrm{N}-\mathrm{O})^{26}$. Posteriormente hemos podido fechar con precisión esta gran intervención gracias a una entrada de los libros de fábrica fechada en $1781^{27}$.

Por esos años, la opinión desfavorable hacia el aspecto de la nave cubierta con madera y del fuerte contraste que producía su comparación con el noble crucero fueron los argumentos esgrimidos para acometer el «embovedado» del espacio destinado a los fieles (Fig. 15). El tracista propone una ampliación en la que, pese a su natural y lógica vinculación con el estilo barroco dominante, el resultado final no produce una ruptura radical respecto del proyecto románico. El aula se divide en tres naves separadas por pilares que sostienen arcos de medio punto y las cubiertas son de crucería para la central y de arista en las laterales.

Al exterior (A 111), esta obra combina sillería, mampuestos, ladrillos y material reutilizado ${ }^{28}$, extendiéndose hasta la fachada occidental que alberga el coro interior (UE 1075). Pese a su heterogeneidad, posee una clara uniformidad estratigráfica e incluye varios vanos entre los que destaca por su buena labra la puerta de

\footnotetext{
25 Los hermanos Gregorio y Fernando de la Sierra, vecinos de Almazán, se encargaron de desmontar y tajar la piedra de la capilla (ADO-S, Libro 38/34, ff. 179v-180r 1762, diciembre, 30).

26 Como ya adelantamos, la adecuada comprensión de esta gran intervención de cuño barroco requirió de una estrategia concreta, puesto que todo el interior de la misma se encuentra oculta al interior por enfoscados pluriseculares (UE 1165). Fue la combinación de los datos indirectos sumados al análisis configuracional derivado de la tipologización de sus basas, entablamentos, ménsulas y plafones los que permitió superar el obstáculo que supone la invisibilidad de la estratigrafía.

27 ADO-S, Libro 38/34, s.f., r-r-v-r-v 1781, mayo, 25.

28 Algunas piezas de época medieval se aprecian a simple vista en el hastial occidental; sillares románicos, tambores de columnas, secciones de nervaduras góticas e incluso lápidas sepulcrales.
}

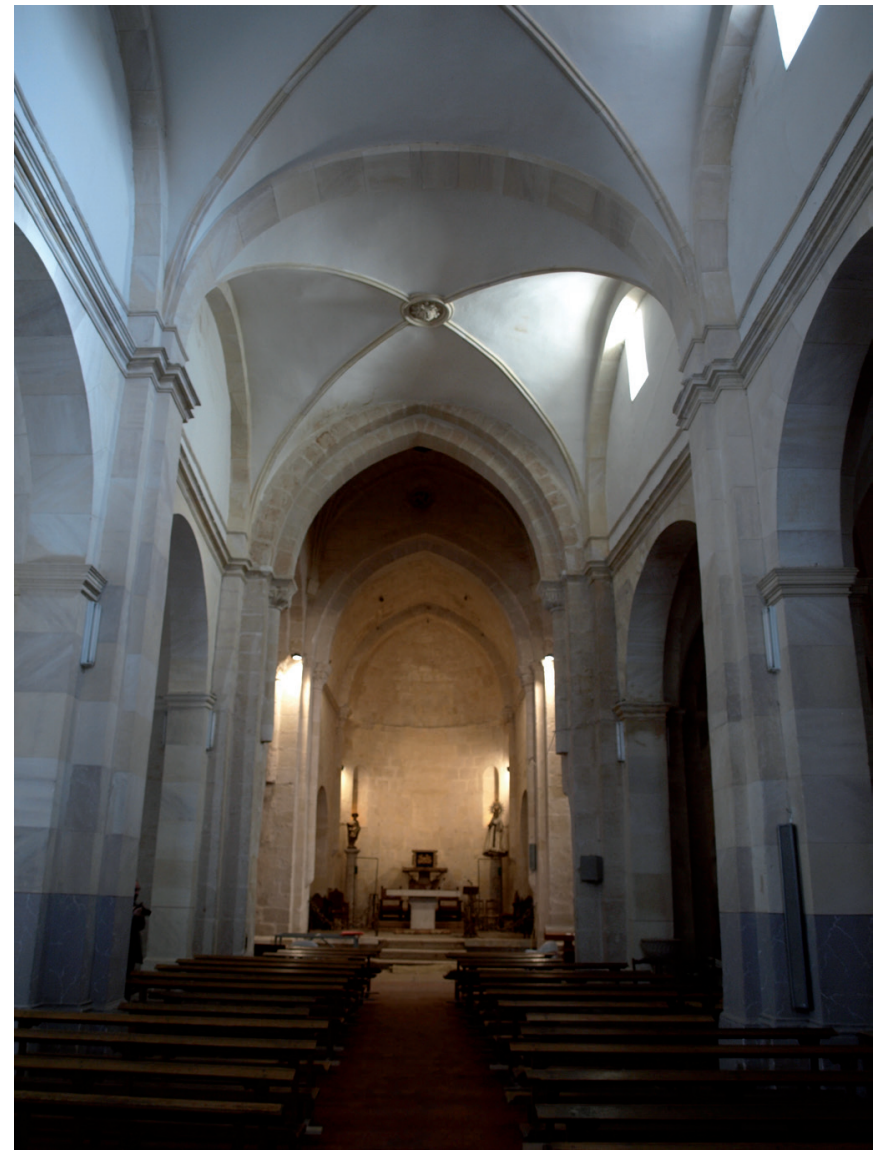

Fig. 15. Nave central del aula desde occidente

piedra abierta en el extremo occidental del muro norte. La apertura de la monumental entrada en este momento responde a la necesidad derivada de la celebración en el templo de los actos públicos del municipio.

Presumimos que es ahora cuando, siguiendo estas mismas coordenadas, se reforman y dignifican algunas partes notables situadas en el costado del templo que se ofrece a la villa. Así interpretamos la elevación de la robusta espadaña con troneras de medio punto para tres campanas ubicada estratégicamente sobre el cierre septentrional del transepto, para proyectar la llamada de campanas hacia el caserío (A 112, UE 1048) ${ }^{29}$.

\footnotetext{
29 A finales del siglo XVIII, de acuerdo con la lectura de las fuentes documentales, se pretendió dignificar algunas partes notables de este templo, que era el utilizado en los actos públicos de la villa. Resulta, no obstante, contradictorio el hecho de que una obra de esta envergadura no quede reflejada en los libros de fábrica. Nos basamos para situarla en esta etapa en argumentos puramente estratigráficos y tipológicos, siendo estos últimos básicos para diferenciarlos de la obra medieval. Un argumento en favor de su correspondencia con este momento constructivo es la posible reutilización de sillares, fragmentos de la cornisa superior y canecillos del remate. Su peso provocó, además, grietas en los paramentos de la fábrica originaria.
} 

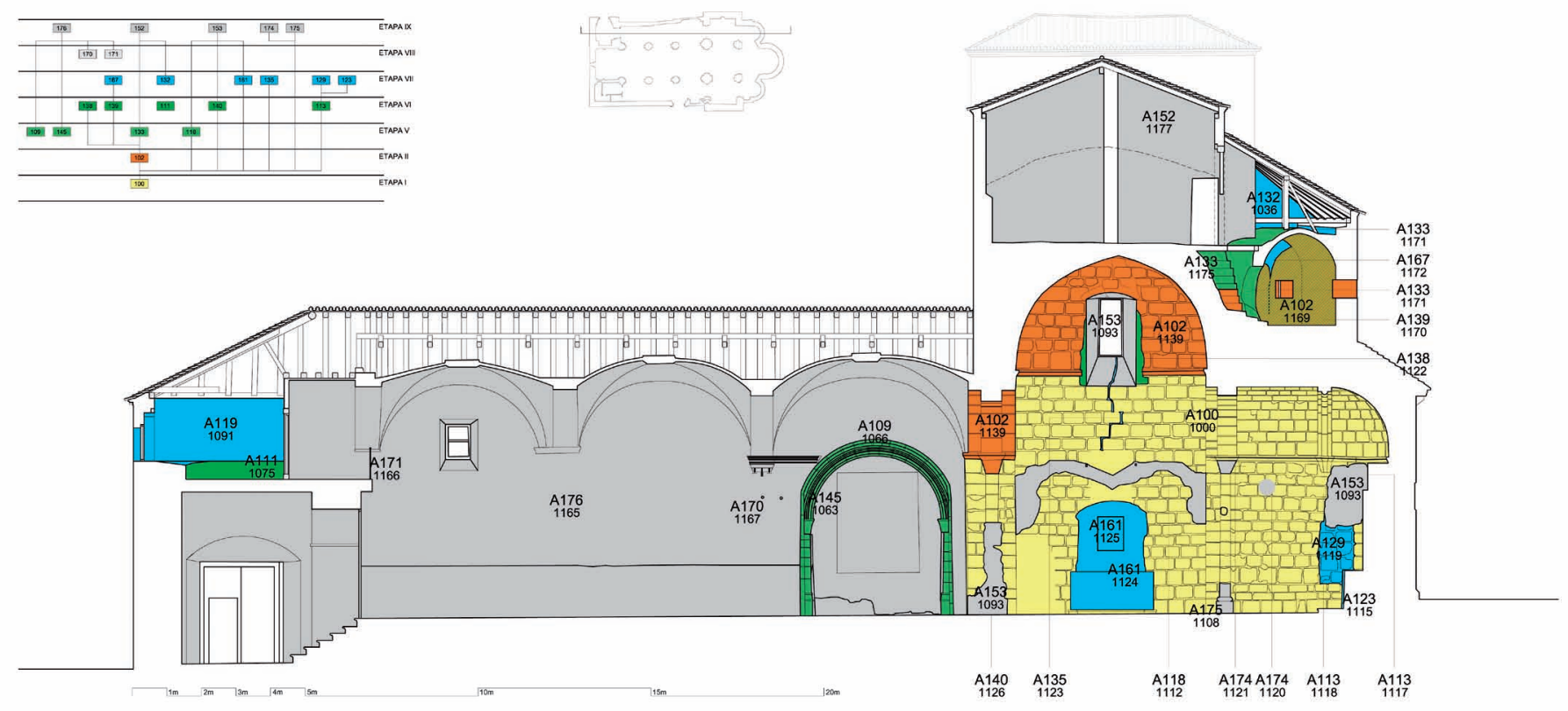

Fig. 16. Alzado interior norte de la nave y el ábside septentrional

\section{Etapa VII. Reparación de los desperfectos tras la Guerra de la Independencia y obras decimonónicas}

Llama la atención el hecho de que, transcurridos apenas unos lustros desde su reforma, se detecten obras de reparación en numerosas partes del edificio. Un rápido recuento de las zonas afectadas nos traslada a los tramos intermedios del muro norte (A 119), la esquina noroeste del cuerpo occidental (UE 1074, 1091), casi la totalidad de la nave central en su muro sur al exterior (A 120; UE 1088 y 1099), parte de la cámara suprabsidal norte (A 167, UE 1172) y, además, la torre del crucero (Fig. 16).

Las relaciones estratigráficas del cimborrio son claras al respecto puesto que su cierre oeste (coetáneo al resto de sus muros perimetrales) se prolonga perpendicularmente hasta adosarse al de la espadaña moderna, respecto a la cual es posterior (Fig. 17). Se deduce entonces que este espacio (A 124) fue reconstruido tras la elevación del campanario con el único fin de recuperar la estructura que soportaba la bóveda gótica, de ahí el aspecto desordenado de su trasdós que, por otro lado, no posee indicios de haber tenido cubierta ${ }^{30}$.

\footnotetext{
30 Esta irremediable incertidumbre estructural se verá inmediatamente oculta mediante el realce de todos los muros del transepto (A 132). En la actualidad esta reparación es solamente visible cuando se accede al bajocubierta y el «envoltorio» constructivo que la camufla fue completado ya en el siglo XX con ladrillo hueco (UE 1064) para proporcionar el curioso aspecto externo del tramo del crucero de la iglesia.
}

¿Por qué acometer ahora obras de tal envergadura cuando a fines del siglo anterior se había remozado casi por completo? La respuesta hemos de buscarla en los dramáticos acontecimientos acaecidos en Almazán durante el asedio de las tropas napoleónicas durante la Guerra de la Independencia.

Por su posición estratégica y privilegiada, este templo había sido desde antaño considerado entre los edificios más fuertes del municipio. Pese a no contar con datos precisos, parece plausible que en la jornada más sangrienta (el 10 de julio de 1810) fuera utilizada como bastión para su defensa $y$, en consecuencia, le fueran infringidos serios daños. Ese día, tras los duros combates que suceden al asedio al que someten las tropas francesas dirigidas por el capitán Basté a los guerrilleros refugiados, se produjo un terrible incendio que afectó a gran parte del trazado urbano. Tal es así, que no se guarda memoria escrita de los desperfectos hasta algunos meses más tarde, si bien el dato es de notable importancia para nuestro estudio puesto que en el acta del pleno del ayuntamiento con fecha de 13 de noviembre se recogen las declaraciones de un capellán, que describe los grandes destrozos que sufrió la villa, especialmente en los lugares sagrados ${ }^{31}$. Pese al

\footnotetext{
31 Gómez, J. L. y Espinosa de los Monteros, J. M. 2011: “Almazán durante la guerra de la Independencia”, Conferencia dictada en Almazán el día 1 de octubre de 2011 [en línea] < http://www.gomezurdanez.com/almazan.pdf $>$ [consultado el 18/08/2014].
} 


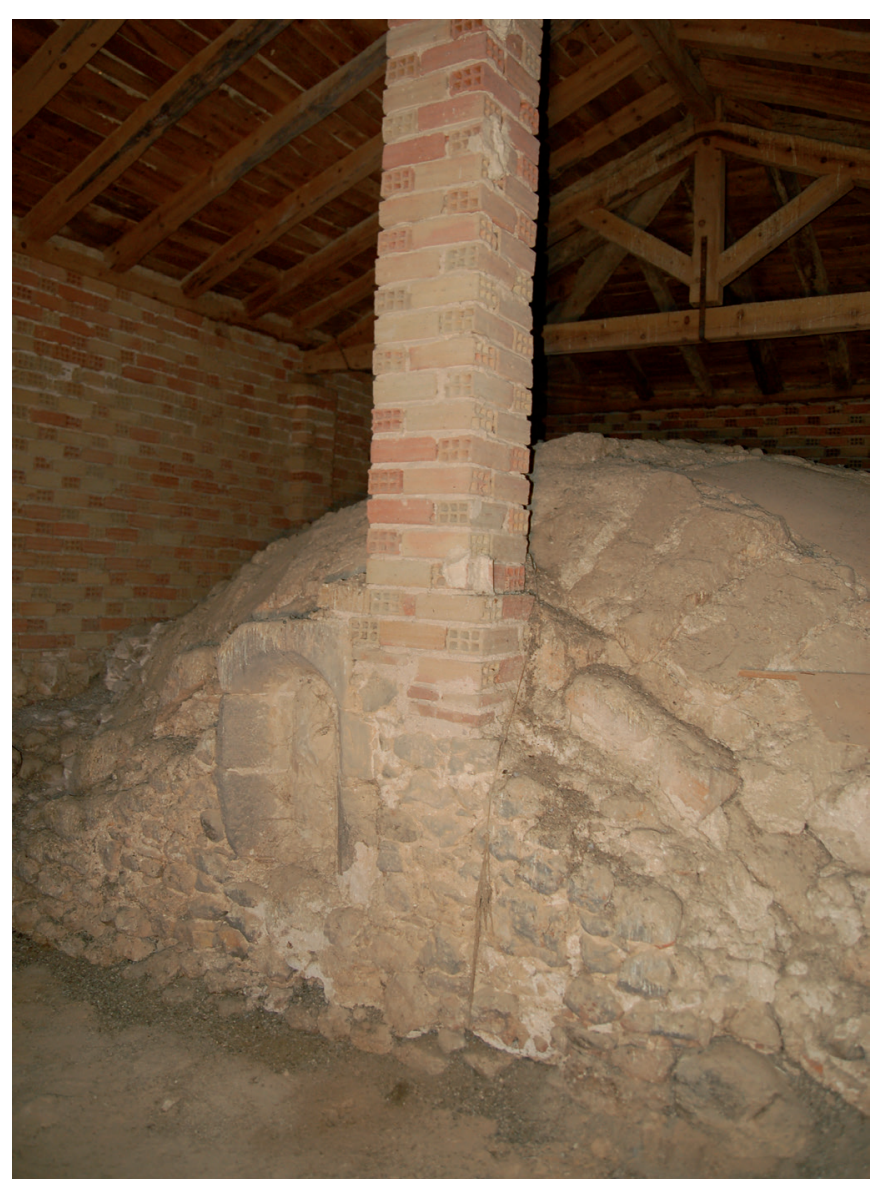

Fig. 17. Trasdós del cimborrio e intervención contemporánea bajocubierta

carácter general de la cita, es posible que uno de estos edificios damnificados fuera la iglesia de Ntra. Sra. de Campanario, lo que justificaría la actividad reconstructora que situamos en los primeros decenios del siglo XIX.

No podemos asegurar la relación entre la reparación de todos estos desperfectos y la instalación de ciertos elementos de corte neoclásico para los que contamos con referencias que los datan en el siglo XIX. Así sucede con la puerta meridional (A 122) y el recubrimiento con placas de piedra $^{32}$ de las zonas aledañas que muestra una inscripción con la fecha de 1848 y los altares actualmente expuestos en las capillas laterales.

\section{Etapa VIII y IX. El siglo XX}

La agitada andadura del templo por el siglo anterior da paso en el XX al inicio de ciertas intervenciones restauradoras que persiguen recuperar parcialmente la imagen del edificio medieval. En la que hemos denominado

\footnotetext{
32 Cuya técnica de talla, con guía y bujarda, se diferencia notablemente de la fábrica románica que corta.
}

etapa VIII esta intención parece ya desprenderse de la liberación en el lado norte de estancias adosadas (A 157, UE 1071).

Un mayor carácter «repristinador» poseen las actividades recogidas en la novena y última etapa documentada, referida a las restauraciones efectuadas desde mediados del siglo pasado. Es posible agrupar las intervenciones en dos grandes bloques en función de las técnicas utilizadas con ese propósito.

Un primer bloque lo compondrían acciones escasamente profesionalizadas y con un evidente componente popular. También son las más antiguas de este periodo. En primer lugar la cabecera fue liberada de estructuras adosadas (A 154) desmontando también las que todavía permanecían en el lado norte (A 156). En los años 70 las gentes del pueblo, que con dicha tarea compensaban parte de sus obligaciones fiscales, se afanaron en picar con bujarda todos los paramentos de la cabecera para extraer la obra románica de los revestimientos pluriseculares para, posteriormente, rejuntar la fábrica de sillería. No cabe duda de que el empeño puesto fue tan intenso como efectivo, puesto que la acción afectó a todos los muros de la cabecera desde el pavimento hasta las bóvedas (A 174, UE 1178), incluyendo elementos ornamentados que sufrieron daños irreparables (UE 1121).

Tampoco resulta afortunada, ni material ni estéticamente, la decisión de recrecer con ladrillo hueco todos los muros del área del crucero sobre el cimborrio recuperado para crear una falsa torre cúbica que se prolonga hasta adosarse contra la espadaña que se recubre de un enfoscado pardo que simula el color de la piedra (A 152).

Por último, hemos recogido las restauraciones recientes en las que se utiliza un mortero arenoso ${ }^{33}$ mediante el cual se recuperan las formas de ciertos elementos románicos como ventanas, basas, pilares y columnas (A 175; UE 1094, 1108). Esta misma técnica, pero aplicando sobre la argamasa terrosa aún fresca una rejilla para imitar la superficie de la piedra y trazos del despiece, se utiliza para cubrir lagunas en las fases románicas (UE 1093, 1146). Especialmente llamativo resulta el uso de este mismo trampantojo al interior del cimborrio sobre el crucero donde se simula un perfecto acabado en sillería cuando, en realidad, el muro es de mampostería (UE 1152).

\footnotetext{
El gran porcentaje de áridos en el mortero, principalmente arena de miga, ha provocado que en las partes bajas del edificio, sometidas a la humedad, esté desapareciendo.
} 


\section{5.- Conclusiones}

La lectura estratigráfica de la iglesia soriana de Ntra. Sra. de Campanario ha arrojado resultados que, a nuestro entender, incrementan sustancialmente el conocimiento sobre su origen y evolución constructiva. De manera global, los objetivos alcanzados se sitúan en dos horizontes diferentes pero estrechamente imbricados: la comprensión del desarrollo constructivo del edificio y la aproximación a las funciones originarias concedidas a algunos de sus espacios singulares.

Pese a que su aspecto se alejara, a ojos de los eruditos decimonónicos formalistas, del de los edificiosmodelo, estilísticamente hablando, nosotros valoramos esta cualidad entre sus principales valores. Es esta morfología ciertamente ecléctica la que ha salvaguardado espacios «únicos» hoy desaparecidos en otros ejemplos románicos, así como también ha permitido estudiar con precisión la azarosa historia de su construcción.

Suponemos que también se debe a este mismo estigma formal el hecho de que, pese a tratarse de uno de los edificios románicos de mayores dimensiones de la provincia, su estudio apenas haya repercutido en la historiografía contemporánea. La principal conclusión que se desprende del repaso por la investigación previa es que la mayoría de los autores venían centrando su interés en establecer una cronología inicial para el templo, siendo apenas Rodríguez (2002) el único en establecer algunos pautas para el desarrollo posterior del mismo. Quedaban pendientes de resolución algunos interrogantes fundamentales: ¿llegó a tener un aula acorde con la cabecera levantada en este periodo? y, de ser así, ¿de qué manera se alcanzó este aspecto «ecléctico» que hoy muestra?

El análisis estratigráfico nos ha permitido establecer un total de nueve etapas que jalonan de manera desigual el desarrollo constructivo del templo, desde el proyecto originario románico hasta nuestros días. Sin embargo, no todas ellas han de ser entendidas como acciones herméticas o inconexas que redefinan la estructura precedente, pudiéndose algunas considerar como parte de un mismo empeño arquitectónico cuyas alteraciones provocan diacronías merecedoras de ser individualizadas.

Así sucede con lo que podría catalogarse como «obra románica», que hemos acordado extender a las tres primeras etapas. Durante la primera se lleva a cabo la elevación de la gran cabecera y se establece el perímetro del transepto y parte del aula. Se marca así la pauta típicamente románica de tres ábsides semicircula- res en batería, transepto destacado y aula, presumimos, tripartita y alzado basilical. Se ha podido confirmar que este diseño primigenio incluía el husillo en la esquina SO del transepto, imaginamos que como parte de un sistema de acceso a las partes altas del edificio. No obstante, desconocemos algunos elementos singulares de esta primera fábrica, tales como las ventanas de los ábsides, pero sí estamos en disposición de asegurar que ya entonces se proyecta la edificación de un aula completamente abovedada para la cual se construyen los soportes compuestos que la comunican con el crucero. Para este planteamiento arquetípicamente románico se opta por una fábrica de sillares con abundantes marcas de cantero, dato que será muy importante para su identificación al interior, donde las alteraciones del siglo XX ocultan las relaciones entre las unidades. También forma parte de la obra un taller de escultores en el que se puede proponer un maestro aventajado, que talla los capiteles del ábside central, y uno de menor calidad que trabaja en los de los laterales.

La observación detallada de estos rasgos tipológi$\cos \mathrm{y}$ ornamentales ha permitido establecer una fractura entre esta primera etapa y la segunda, si bien ésta obedece a un replanteamiento del proyecto inicial. Se reduce el tamaño de los sillares y apenas existen marcas de cantero en piezas distribuidas en hiladas irregulares. Concluidas las bóvedas pétreas de las tres capillas, es ahora cuando se genera un gran espacio aterrazado sobre ellas, instalándose las cámaras suprabsidales ${ }^{34}$ dispuestas a modo de artesa sobre los ábsides norte y sur. Ante la ausencia de documentación que precise su función, hemos barajado las hipótesis de considerarlas lugares de almacenamiento, de devoción o defensa, siendo ésta última la que pensamos mejor se adapta a sus características edilicias y ubicación topográfica. Al exterior, tal intervención genera un aspecto abaluartado sobre la cabecera, cobrando sentido pleno el husillo iniciado durante la primera fase, que se completará ahora.

La otra gran aportación de esta segunda etapa es la elevación de las bóvedas de cañón apuntado en los brazos del transepto, y suponemos también que de otra (sustituida a finales del gótico) en el crucero. Aparejo y motivos ornamentales, en tanto que siguen las variables anteriormente expuestas, apoyan su cronología románica que viene avalada por la tipología de la propia cubierta. De esta manera, al finalizar la segunda fase constructiva, se podría contemplar un edificio masivo y esbelto, como

\footnotetext{
34 Que, a falta de comprobación precisa, consideramos eran dos.
} 
resultado de la inclusión de sendos espacios fuertes en el frente oriental y del hecho de que, según nuestra lectura, no se haya procedido a la construcción del espacio reservado para los fieles. Así las cosas, y de acuerdo con la tónica habitual en las edificaciones religiosas medievales, la consagración del templo pudiera haberse realizado ahora o incluso en la etapa anterior.

En la tercera fase se procede a fijar el perímetro del aula, así como a la cubierta de la misma, si bien parece que dejando de lado las coordenadas establecidas en el proyecto original. Se aprecia un notable descenso en la calidad de los materiales empleados, fundamentalmente muros de mampostería, reservándose la piedra labrada para elementos singulares. Así sucede con los arcos de separación entre las naves, de los que se ha podido localizar el despiece de uno fosilizado en la obra posterior del muro sur de la nave central. Se trata de un gran arco formero de perfil ojival y amplia luz, ciertamente medieval pero incompatible con los pilares compuestos de la obra anterior y sustancialmente distinto a los arcos y bóvedas de las etapas I y II. Interpretamos esta arquería, que no podemos llevar más allá de un único tramo, como una solución de contingencia que tiene como misión concluir el edificio y que, como veremos, pudo soportar una techumbre de madera.

Finalizada esta tercera etapa, podemos decir que el edificio posee con seguridad todos los elementos que aseguran la finalización de las obras. Se trata de un proceso lento y, probablemente, con un profundo replanteamiento al acometer la compartimentación y cubrición de las naves. Parece sensato pensar que la cubierta de madera de la nave sobre formeros apuntados de amplia luz debió instalarse abandonado ya el románico más ortodoxo y dentro de cronologías propias del gótico.

$\mathrm{Su}$ aspecto actual se ha ido forjando a través de modificaciones de distinto calado que, con mayor o menor intensidad, son deudoras de las corrientes estilísticas dominantes en el momento en que fueron proyectadas. La lectura de paramentos nos permite secuenciarlas con independencia de sus rasgos formales puesto que hay ocasiones en las que, como sucede con el cimborrio gótico, un análisis exclusivamente taxonómico puede conducirnos a una comprensión errónea de la evolución del edificio.

\section{Agradecimientos y Ficha técnica}

Este trabajo resume en lo esencial el informe arqueológico resultante de la lectura de paramentos de la iglesia de Nuestra Señora de Campanario (Moreno, F. y Murillo,

\section{J. I. 2010: Iglesia de Nuestra Señora de Campanario} en Almazán (Soria). Lectura de paramentos). El trabajo fue encargado por la Fundación Duques de Soria en el marco del Proyecto Cultural Soria Románica. Asesor científico: L. Caballero (IH, CSIC). Trabajo de campo: José Ignacio Murillo (arqueólogo, tratamiento de la planimetría), Francisco J. Moreno (historiador del arte, redacción de la memoria, UCM), María de los Ángeles Utrero (arqueóloga, IH, CSIC), Carlos Cauce (arqueólogo, IH-CSIC), Rafael Martín (arquitecto, planimetría original, UPM) y Francisco Martínez (arquitecto, UPM). Supervisión: Equipo Técnico del Proyecto Cultural Soria Románica. Fundación Duques de Soria. Recopilación de la documentación en archivo. Josemi Lorenzo (historiador, Proyecto Cultural Soria Románica). Agradecemos a José Ángel Márquez, del Ayuntamiento de Almazán, las valiosas referencias que ayudaron a la adecuada contextualización de parte de los resultados del trabajo. Por último, nos gustaría dejar constancia de cómo las acertadas indicaciones de los evaluadores del texto han enriquecido su contenido ${ }^{35}$.

La autoría de las figuras es de los autores, salvo aquellas que poseen referencias concretas.

\section{Bibliografía}

Alcolea Gil, S. 1964: Soria y su provincia. Guías artística de España. Ariel, Barcelona

Bango Torviso, I. G. 1997-1998: "El verdadero significado del aspecto de los edificios. De lo simbólico a la realidad funcional. La iglesia encastillada", Anuario del Departamento de Historia y Teoría del Arte, 9-10, pp. 53-71.

Boto Varela, G. 2008: "Capillas en alto y cámaras elevadas en templos románicos hispanos: morfologías, usos litúrgicos y prácticas cultuales”, en Espacios y estructuras singulares del edificio románico, pp. 93-119, Fundación Santa María la Real, Aguilar de Campoo.

Carrete, C. y Fraile, C. 1987: Los judeoconversos de Almazán, 1501-1505. Origen familiar de los Lainez. Fontes Iudaeorum Regni Castellae, IV, Ediciones de la Universidad, Salamanca.

Diago Hernando, M. 1993: “Almazán en época de los Reyes Católicos. Estructura social de una pequeña capital de Estado señorial”, En la España Medieval, 16, pp. 239-264.

Dimanuel Jiménez, M. 2006: "Estructuras y elementos militares en iglesias fortificadas medievales españolas", Anales de Historia del Arte, 16, pp. 79-102.

Gaya Nuño, J. A. 1946: El románico en la provincia de Soria, CSIC, Madrid.

Herrero, J. y Márquez, J. A. 1994: La platería en Almazán, Ayuntamiento de Almazán, Almazán.

Huerto, J. del. y Frías, T. 1991: Guía de Almazán, Centro de iniciativas y turismo D.L., Soria.

\footnotetext{
35 Hemos recogido la mayoría de sus sugerencias y sólo en ocasiones mínimas hemos considerado omitirlas. En concreto nos referimos a la propuesta de diseñar una planta cromática evolutiva que, en nuestra opinión no aportaría mucha más información de la que proporcionan los planos publicados. Como hemos puesto de manifiesto en el texto, la riqueza estratigráfica del edificio se produce mayoritariamente en lo referido a sus alzados y no tanto a su perímetro.
} 
López de Ayala, J. 1991: Crónicas, Edición, prólogo y notas de J. L. Martín, Planeta, Barcelona.

Madoz Ibáñez, P. 1845: Diccionario geográfico-estadístico-histórico de España y sus posesiones de Ultramar, tomo 2, s. n., Madrid.

Mannoni, T. 1998: "Analisi archeologiche degli edifici con strutture portante non visibili", Archeologia dell'Architettura, 3, pp. 81-85.

Márquez Muñoz, J. A. 1987: "Una comunidad de villa y tierra de la Extremadura castellana: Almazán hasta el siglo XIII", Celtiberia, 37, 73, pp. 21-69.

Martín Ansón, M. L. 2008: "El tesoro sagrado de los monasterios cistercienses hispanos: entre la austeridad y la opulencia”, en Monasterios cistercienses en la España Medieval, pp. 181-213, Fundación Santa María la Real, Aguilar de Campoo.

Martínez Frías, J. M. 1980: El gótico en Soria. Arquitectura y escultura monumental, Editorial Universidad de Salamanca, Salamanca.

Minguella y Arnedo, T. 1912: Historia de la diócesis de Sigüenza y de sus obispos, vol. 2, Imprenta de la Revista de Archivos, Bibliotecas y Museos, Madrid.

Muñoz Sánchez, J. M. 1990: “La villa de Almazán: estudio histórico-geográfico" en Congreso de jóvenes historiadores y geógrafos, Actas, 1, pp. 89-97, Universidad Complutense, Madrid.
Nuño González, J. 2002: "Detrás de los artístico: otras formas de mirar el edifico románico", en Perfiles del Arte Románico, pp. 111-143, Fundación Santa María la Real, Aguilar de Campoo.

Nuño González, J. 2008: "Las iglesia rurales en la Ribera del Duero en época románica: un variado papel dentro de una sociedad en formación”, en $E l$ Medievo en el Duero Oriental. Historia y Arte Románico, Biblioteca, Estudio e Investigación, 23, pp. 137-159, Ayuntamiento de Aranda de Duero, Aranda de Duero.

Ortego y Frías, T. 1973: Almazán, ilustre villa soriana, Caja General de Ahorros y Préstamos de la Provincia, Madrid.

Pérez-Rioja, J. A. 1970: Guía turística de Soria y su provincia, IMNASA, Madrid.

Rodríguez Montañés, J. M. 2002: "Iglesia de Nuestra Señora del Campanario", en Enciclopedia del Románico en Castilla y León. Soria, vol. 1, pp. 150-154, Fundación Santa María la Real, Aguilar de Campoo.

Sainz Magaña, E. 1984: El románico soriano: estudio simbólico de los monumentos, Universidad Complutense de Madrid, Madrid

Taracena, B. y Tudela, J. 1962: Guía artística de Soria y su provincia, Revista de Occidente, Madrid.

Tudela de la Orden, J. 1962: “Almazán, corte de los Reyes Católicos”, Celtiberia, 12, 24, pp. 169-195.

\section{Apéndice I. Listado de Actividades}

\begin{tabular}{|c|c|c|c|c|c|c|}
\hline $\mathbf{P}$ & Act & Nombre Act & $\mathbf{U E}$ & Nombre UE & Ant a Act & Post a Act \\
\hline \multirow[t]{2}{*}{ I } & 100 & $\begin{array}{l}\text { Construcción cabecera y } \\
\text { transepto }\end{array}$ & 1000 & $\begin{array}{l}\text { Cabecera triabsidiada, presbiterios y } \\
\text { parte inferior del transepto. }\end{array}$ & $\begin{array}{llll}101 & 102 & 103 \\
106 & 107 & 109 \\
113 & 114 & 115 \\
117 & 122 & 124 \\
126 & 127 & 128 \\
129 & 130 & 134 \\
136 & 135 & 137 \\
140 & 141 & 142 \\
143 & 145 & 147 \\
148 & 149 & 151 \\
153 & 154 & 159 \\
161 & 162 & 164 \\
168 & 169 & 172 \\
174 & 175 & \end{array}$ & \\
\hline & & $\begin{array}{l}\text { Construcción cabecera y } \\
\text { transepto }\end{array}$ & 1140 & $\begin{array}{l}\text { Partes inferiores de los pilares } \\
\text { compuestos entre aula y transepto. }\end{array}$ & $\begin{array}{lll}102 & 115 & 116 \\
140 & 158 & 174\end{array}$ & \\
\hline I & 101 & Vano meridional & 1154 & $\begin{array}{l}\text { Rosca e imposta de arcosolio en muro } \\
\text { sur interior. }\end{array}$ & $\begin{array}{l}100122153 \\
163165\end{array}$ & \\
\hline \multirow[t]{3}{*}{ II } & 102 & $\begin{array}{l}\text { Sobre elevación ábsides y } \\
\text { cubierta transepto }\end{array}$ & 1034 & $\begin{array}{l}\text { Gran fábrica de sillería en parte alta } \\
\text { de los testeros del transepto, husillos y } \\
\text { hastial. }\end{array}$ & $\begin{array}{lll}103 & 104 & 106 \\
112 & 122 & 131 \\
132 & 133 & 134 \\
135 & 138 & 145 \\
152 & & \end{array}$ & 100 \\
\hline & & $\begin{array}{l}\text { Sobre elevación ábsides y } \\
\text { cubierta transepto }\end{array}$ & 1139 & $\begin{array}{l}\text { Obra de sillería en partes altas interior } \\
\text { que incluye arcos, bóvedas y capiteles. }\end{array}$ & $\begin{array}{lll}115 & 118 & 124 \\
135 & 138 & 153 \\
160 & 175\end{array}$ & 100 \\
\hline & & $\begin{array}{l}\text { Sobre elevación ábsides y } \\
\text { cubierta transepto }\end{array}$ & 1169 & $\begin{array}{l}\text { Cámara abovedada y pasillo acceso con } \\
\text { escalera. }\end{array}$ & $\begin{array}{l}133139148 \\
152\end{array}$ & \\
\hline
\end{tabular}




\begin{tabular}{|c|c|c|c|c|c|c|}
\hline $\mathbf{P}$ & Act & Nombre Act & $\mathbf{U E}$ & Nombre UE & Ant a Act & Post a Act \\
\hline \multirow[t]{2}{*}{ II } & 103 & $\begin{array}{l}\text { Límite occidental cuerpo } \\
\text { superior transepto }\end{array}$ & 1059 & $\begin{array}{l}\text { Solución vertical entre las UE } 1034 \text { y } \\
1057 \text {, cara oeste, transepto norte. }\end{array}$ & 104 & 102 \\
\hline & & $\begin{array}{l}\text { Límite occidental cuerpo } \\
\text { superior transepto }\end{array}$ & 1077 & $\begin{array}{l}\text { Solución de continuidad vertical entre } \\
\text { UE } 1034 \text { y } 1078 \text { en el muro oeste del } \\
\text { transepto sur. }\end{array}$ & 104 & 102 \\
\hline II & 130 & Fisuras en sillería cabecera & 1033 & $\begin{array}{l}\text { Fisuras en algunos sillares de la fábrica } \\
\text { románica. }\end{array}$ & & 100 \\
\hline \multirow[t]{3}{*}{ III } & 104 & $\begin{array}{l}\text { Alzado exterior occidental } \\
\text { transepto }\end{array}$ & 1057 & $\begin{array}{l}\text { Fábrica de mampuestos grandes en cara } \\
\text { oeste, exterior, transepto norte. }\end{array}$ & 112132145 & 103 \\
\hline & & $\begin{array}{l}\text { Alzado exterior occidental } \\
\text { transepto }\end{array}$ & 1076 & $\begin{array}{l}\text { Cuatro tejas de piedra en parte superior } \\
\text { del husillo. }\end{array}$ & & 102 \\
\hline & & $\begin{array}{l}\text { Alzado exterior occidental } \\
\text { transepto }\end{array}$ & 1078 & $\begin{array}{l}\text { Obra mampostería cara oeste brazo sur } \\
\text { transepto. }\end{array}$ & 132152 & 103 \\
\hline \multirow[t]{2}{*}{ III } & 105 & $\begin{array}{l}\text { Formeros primer tramo } \\
\text { arquerías }\end{array}$ & 1085 & $\begin{array}{l}\text { Muro con arco de piedra en lado sur, } \\
\text { nave central. }\end{array}$ & 152 & \\
\hline & & $\begin{array}{l}\text { Formeros primer tramo } \\
\text { arquerías }\end{array}$ & 1164 & $\begin{array}{l}\text { Huellas del arco en piedra parte alta nave } \\
\text { central (lado norte). }\end{array}$ & & \\
\hline \multirow[t]{3}{*}{ IV } & 106 & $\begin{array}{l}\text { Capilla en primer tramo } \\
\text { nave norte }\end{array}$ & 1051 & Obra para capilla gótica en lateral norte. & 109110 & 100 \\
\hline & & $\begin{array}{l}\text { Capilla en primer tramo } \\
\text { nave norte }\end{array}$ & 1056 & $\begin{array}{l}\text { Huella vertical esquina norte-oeste } \\
\text { testero transepto norte. }\end{array}$ & & 100 \\
\hline & & $\begin{array}{l}\text { Capilla en primer tramo } \\
\text { nave norte }\end{array}$ & 1060 & $\begin{array}{l}\text { Roza oblicua en cara oeste del brazo } \\
\text { norte de transepto, exterior. }\end{array}$ & & 100102 \\
\hline IV & 117 & Apertura arcosoleo & 1183 & Apertura arcosolio testero sur transepto. & 161 & 100 \\
\hline IV & 127 & Grabados ábsides & 1004 & $\begin{array}{l}\text { Grafitis e inscripciones exteriores } \\
\text { (medievales). }\end{array}$ & & 100 \\
\hline IV & 163 & $\begin{array}{l}\text { Instalación hojas puerta } \\
\text { acceso original }\end{array}$ & 1156 & $\begin{array}{l}\text { Corte de trasdós e intradós de arco de UE } \\
1154 .\end{array}$ & 165 & 101 \\
\hline \multirow[t]{4}{*}{$\mathrm{V}$} & 107 & $\begin{array}{l}\text { Apertura arcos } \\
\text { interabsidales }\end{array}$ & 1102 & $\begin{array}{l}\text { Corte en las cuatro columnas presbiterio } \\
\text { ábside central. }\end{array}$ & 147153 & 100 \\
\hline & & $\begin{array}{l}\text { Apertura arcos } \\
\text { interabsidales }\end{array}$ & 1103 & $\begin{array}{l}\text { Apertura arcos comunicación entre } \\
\text { ábsides laterales y presbiterio. }\end{array}$ & 147174177 & 100 \\
\hline & & $\begin{array}{l}\text { Apertura arcos } \\
\text { interabsidales }\end{array}$ & 1116 & $\begin{array}{l}\text { Corte de semicolumna del lado sur } \\
\text { embocadura ábside norte. }\end{array}$ & & 100 \\
\hline & & $\begin{array}{l}\text { Apertura arcos } \\
\text { interabsidales }\end{array}$ & 1129 & $\begin{array}{l}\text { Corte semicolumna norte en embocadura } \\
\text { ábside sur. }\end{array}$ & & 100 \\
\hline $\mathrm{V}$ & 108 & Interior puerta meridional & 1162 & $\begin{array}{l}\text { Puerta adintelada y abocinada en muro } \\
\text { sur. }\end{array}$ & & \\
\hline $\mathrm{V}$ & 109 & $\begin{array}{l}\text { Reforma arco acceso capilla } \\
\text { norte }\end{array}$ & 1066 & $\begin{array}{l}\text { Arco de medio punto de acceso a capilla } \\
\text { gótica y tímpano más jambas. }\end{array}$ & 125136150 & 106 \\
\hline \multirow[t]{2}{*}{$\mathrm{V}$} & 114 & Sacristía & 1009 & $\begin{array}{l}\text { Rotura de sillar en paño sur del ábside } \\
\text { central. }\end{array}$ & 153 & 100 \\
\hline & & Sacristía & 1010 & $\begin{array}{l}\text { Roza oblicua en paño sur del ábside } \\
\text { central. }\end{array}$ & 153154 & 100 \\
\hline
\end{tabular}




\begin{tabular}{|c|c|c|c|c|c|c|}
\hline $\mathbf{P}$ & Act & Nombre Act & UE & Nombre UE & Ant a Act & Post a Act \\
\hline & & Sacristía & 1023 & $\begin{array}{l}\text { Gran roza horizontal en parte alta del } \\
\text { ábside sur, presbiterio y transepto. }\end{array}$ & 153154 & 100 \\
\hline & & Sacristía & 1024 & $\begin{array}{l}\text { Corte en jamba izquierda de ventana } \\
\text { ábside sur. }\end{array}$ & 154 & 100 \\
\hline & & Sacristía & 1025 & $\begin{array}{l}\text { Pareja de agujeros rectangulares en } \\
\text { exterior ábside sur. }\end{array}$ & 153154 & 100 \\
\hline & & Sacristía & 1026 & Restos de enlucido blanco. & & 100 \\
\hline & & Sacristía & 1027 & $\begin{array}{l}\text { Agujero sobre ventana del ábside } \\
\text { meridional. }\end{array}$ & & 100 \\
\hline & & Sacristía & 1029 & Gran agujero esquina sur ábside sur. & & 100 \\
\hline & & Sacristía & 1030 & $\begin{array}{l}\text { Tres huecos tramo recto sur ábside } \\
\text { meridional. }\end{array}$ & & 100 \\
\hline & & Sacristía & 1031 & $\begin{array}{l}\text { Tres huecos atizonados en tramo recto } \\
\text { sur. }\end{array}$ & 153 & 100 \\
\hline & & Sacristía & 1032 & Rotura en tramo recto ábside sur. & 153 & 100 \\
\hline & & Sacristía & 1046 & $\begin{array}{l}\text { Huella vertical en esquina sureste del } \\
\text { testero sur de transepto. }\end{array}$ & & 100 \\
\hline & & Sacristía & 1110 & $\begin{array}{l}\text { Cortes de las semicolumnas del alzado } \\
\text { occidental del transepto. }\end{array}$ & 153175 & 100 \\
\hline & & Sacristía & 1130 & $\begin{array}{l}\text { Apertura de vano en lado sur hemiciclo } \\
\text { ábside sur. }\end{array}$ & 153 & 100 \\
\hline \multirow[t]{3}{*}{$\mathrm{V}$} & 118 & Balconadas transepto & 1112 & $\begin{array}{l}\text { Huellas de arquerías en extremos del } \\
\text { transepto. }\end{array}$ & 153 & 100 \\
\hline & & Balconadas transepto & 1144 & $\begin{array}{l}\text { Agujero rectangular en cara oeste del } \\
\text { brazo norte del transepto. }\end{array}$ & 153 & 102 \\
\hline & & Balconadas transepto & 1160 & $\begin{array}{l}\text { Corte para apertura de camarín dentro de } \\
\text { husillo. }\end{array}$ & 153 & 100 \\
\hline \multirow[t]{3}{*}{$\mathrm{V}$} & 133 & $\begin{array}{l}\text { Transformación cámara } \\
\text { suprábsidal septentrional }\end{array}$ & 1038 & $\begin{array}{l}\text { Rotura en jambas de aspilleras de cámara } \\
\text { supraábside. }\end{array}$ & & 102 \\
\hline & & $\begin{array}{l}\text { Transformación cámara } \\
\text { suprábsidal septentrional }\end{array}$ & 1171 & $\begin{array}{l}\text { Robo o ruina muro lateral oeste entre } \\
\text { cámara y escalera UE } 1169 .\end{array}$ & 166 & 102139 \\
\hline & & $\begin{array}{l}\text { Transformación cámara } \\
\text { suprábsidal septentrional }\end{array}$ & 1175 & $\begin{array}{l}\text { Ampliación escalera UE } 1169 \text { con } \\
\text { madera y mampuesto. }\end{array}$ & & \\
\hline \multirow[t]{3}{*}{$\mathrm{V}$} & 145 & $\begin{array}{l}\text { Elementos desaparecidos } \\
\text { sobre la capilla norte }\end{array}$ & 1061 & $\begin{array}{l}\text { Roza oblicua en cara oeste del brazo } \\
\text { norte del transepto, exterior. }\end{array}$ & & 102104 \\
\hline & & $\begin{array}{l}\text { Elementos desaparecidos } \\
\text { sobre la capilla norte }\end{array}$ & 1062 & $\begin{array}{l}\text { Roza horizontal en cara oeste del brazo } \\
\text { norte del transepto, exterior. }\end{array}$ & & 102 \\
\hline & & $\begin{array}{l}\text { Elementos desaparecidos } \\
\text { sobre la capilla norte }\end{array}$ & 1063 & $\begin{array}{l}\text { Tres agujeros en cara oeste del brazo } \\
\text { norte del transepto, exterior. }\end{array}$ & & 102 \\
\hline \multirow[t]{2}{*}{$\mathrm{V}$} & 148 & $\begin{array}{l}\text { Puerta acceso cámara } \\
\text { suprábsidal desde transepto }\end{array}$ & 1111 & $\begin{array}{l}\text { Corte para puerta junto esquina NE } \\
\text { transepto. }\end{array}$ & 153 & 100 \\
\hline & & $\begin{array}{l}\text { Puerta acceso cámara } \\
\text { suprábsidal desde transepto }\end{array}$ & 1173 & Agujero esquina SO cámara UE 1169. & 139166 & 102 \\
\hline
\end{tabular}




\begin{tabular}{|c|c|c|c|c|c|c|}
\hline $\mathbf{P}$ & Act & Nombre Act & $\mathbf{U E}$ & Nombre UE & Ant a Act & Post a Act \\
\hline $\mathrm{V}$ & 158 & Restos despiece en negro & 1143 & $\begin{array}{l}\text { Restos de pintura negra imitando } \\
\text { despiece en cara sur de pilar sur UE } \\
1140 .\end{array}$ & & 100 \\
\hline $\mathrm{V}$ & 159 & $\begin{array}{l}\text { Huecos posible reja acceso } \\
\text { ábside mayor }\end{array}$ & 1153 & $\begin{array}{l}\text { Huecos en laterales arco de triunfo para } \\
\text { posible rejería. }\end{array}$ & & 100 \\
\hline $\mathrm{V}$ & 160 & Agujeros transepto & 1149 & $\begin{array}{l}\text { Pareja de agujeros enfrentados en parte } \\
\text { alta intradós acceso transepto, nave } \\
\text { central. }\end{array}$ & 175 & 102 \\
\hline $\mathrm{V}$ & 165 & $\begin{array}{l}\text { Pintura interior acceso } \\
\text { original }\end{array}$ & 1157 & $\begin{array}{l}\text { Restos de pintura y agujeros en el interior } \\
\text { del arcosolio. }\end{array}$ & & 101163 \\
\hline $\mathrm{V}$ & 166 & $\begin{array}{l}\text { Adecuación puertas cámara } \\
\text { suprábsidal }\end{array}$ & 1174 & $\begin{array}{l}\text { Reparaciones con adobe y madera de UE } \\
1169 .\end{array}$ & & 133148 \\
\hline $\mathrm{V}$ & 168 & $\begin{array}{l}\text { Límite occidental fachada } \\
\text { original sur }\end{array}$ & 1159 & $\begin{array}{l}\text { Corte en UE } 1000 \text { en muro sur sobre } \\
\text { arcosolio. }\end{array}$ & & 100 \\
\hline $\mathrm{V}$ & 172 & $\begin{array}{l}\text { Agujeros enfrentados ábside } \\
\text { mayor }\end{array}$ & 1105 & $\begin{array}{l}\text { Agujeros bajo imposta tramo central, } \\
\text { lado sur, ábside central. }\end{array}$ & & 100 \\
\hline \multirow[t]{2}{*}{ VI } & 110 & Desmonte capilla norte & 1052 & Relleno de UE 1051. & & 106 \\
\hline & & Desmonte capilla norte & 1065 & $\begin{array}{l}\text { Ruina de la capilla lateral gótica adosada } \\
\text { a nave norte. }\end{array}$ & 136 & 106 \\
\hline \multirow[t]{4}{*}{ VI } & 111 & Aula & 1075 & $\begin{array}{l}\text { Gran obra de sillería, mampuesto y } \\
\text { ladrillo a los pies, oeste, norte y sur. }\end{array}$ & $\begin{array}{l}111119120 \\
122146\end{array}$ & \\
\hline & & Aula & 1082 & $\begin{array}{l}\text { Cegado de ventana en muro sur de UE } \\
1075 .\end{array}$ & & 111 \\
\hline & & Aula & 1083 & Cornisa de teja sobre UE 1075 y 1081. & & 111 \\
\hline & & Aula & 1087 & $\begin{array}{l}\text { Fábrica de ladrillo en zona occidental } \\
\text { exterior muro sur nave central. }\end{array}$ & 121152 & \\
\hline \multirow[t]{2}{*}{ VI } & 112 & Espadaña & 1039 & $\begin{array}{l}\text { Agujero rectangular en lienzo oriental de } \\
\text { espadaña. }\end{array}$ & 174 & \\
\hline & & Espadaña & 1048 & Cuerpo de campanas de espadaña norte. & 132144152 & 102104 \\
\hline \multirow[t]{7}{*}{ VI } & 113 & $\begin{array}{l}\text { Camarín, retablo mayor y } \\
\text { altares secundarios }\end{array}$ & 1005 & Rotura en parte central del ábside central. & 153154 & 100 \\
\hline & & $\begin{array}{l}\text { Camarín, retablo mayor y } \\
\text { altares secundarios }\end{array}$ & 1011 & $\begin{array}{l}\text { Gran rotura paño sur del ábside central } \\
\text { inferior. }\end{array}$ & 153 & 100 \\
\hline & & $\begin{array}{l}\text { Camarín, retablo mayor y } \\
\text { altares secundarios }\end{array}$ & 1012 & $\begin{array}{l}\text { Rotura que abarca varios sillares en paño } \\
\text { sur ábside central. }\end{array}$ & 153 & 100 \\
\hline & & $\begin{array}{l}\text { Camarín, retablo mayor y } \\
\text { altares secundarios }\end{array}$ & 1013 & $\begin{array}{l}\text { Agujero pequeño cuadrado en parte alta } \\
\text { paño sur ábside central. }\end{array}$ & 153 & 100 \\
\hline & & $\begin{array}{l}\text { Camarín, retablo mayor y } \\
\text { altares secundarios }\end{array}$ & 1014 & $\begin{array}{l}\text { Gran rotura junto a ventana en paño norte } \\
\text { ábside central. }\end{array}$ & 153154 & 100 \\
\hline & & $\begin{array}{l}\text { Camarín, retablo mayor y } \\
\text { altares secundarios }\end{array}$ & 1015 & $\begin{array}{l}\text { Grieta que recorre el paño norte del } \\
\text { ábside central. }\end{array}$ & 154 & 100 \\
\hline & & $\begin{array}{l}\text { Camarín, retablo mayor y } \\
\text { altares secundarios }\end{array}$ & 1017 & Huella vertical junto a media columna. & & 100 \\
\hline
\end{tabular}




\begin{tabular}{|c|c|c|c|c|c|c|}
\hline $\mathbf{P}$ & Act & Nombre Act & UE & Nombre UE & Ant a Act & Post a Act \\
\hline & & $\begin{array}{l}\text { Camarín, retablo mayor y } \\
\text { altares secundarios }\end{array}$ & 1092 & Rotura en parte central del ábside mayor. & 153 & 100 \\
\hline & & $\begin{array}{l}\text { Camarín, retablo mayor y } \\
\text { altares secundarios }\end{array}$ & 1095 & Huella blanca en cascarón ábside central. & & 100 \\
\hline & & $\begin{array}{l}\text { Camarín, retablo mayor y } \\
\text { altares secundarios }\end{array}$ & 1096 & $\begin{array}{l}\text { Roturas en las impostas del ábside } \\
\text { central. }\end{array}$ & 153 & 100 \\
\hline & & $\begin{array}{l}\text { Camarín, retablo mayor y } \\
\text { altares secundarios }\end{array}$ & 1098 & $\begin{array}{l}\text { Cinco agujeros de tamaño similar en } \\
\text { hemiciclo absidial. }\end{array}$ & 153 & 100 \\
\hline & & $\begin{array}{l}\text { Camarín, retablo mayor y } \\
\text { altares secundarios }\end{array}$ & 1100 & $\begin{array}{l}\text { Apertura vano alto en hemiciclo ábside, } \\
\text { zona sur. }\end{array}$ & 153 & 100 \\
\hline & & $\begin{array}{l}\text { Camarín, retablo mayor y } \\
\text { altares secundarios }\end{array}$ & 1101 & $\begin{array}{l}\text { Apertura vano bajo en hemiciclo ábside, } \\
\text { zona sur. }\end{array}$ & & 100 \\
\hline & & $\begin{array}{l}\text { Camarín, retablo mayor y } \\
\text { altares secundarios }\end{array}$ & 1109 & $\begin{array}{l}\text { Apertura gran hueco lado norte hemiciclo } \\
\text { ábside central. }\end{array}$ & 153 & 100 \\
\hline & & $\begin{array}{l}\text { Camarín, retablo mayor y } \\
\text { altares secundarios }\end{array}$ & 1117 & $\begin{array}{l}\text { Rotura en lado norte de hemiciclo del } \\
\text { ábside norte. }\end{array}$ & & 100 \\
\hline & & $\begin{array}{l}\text { Camarín, retablo mayor y } \\
\text { altares secundarios }\end{array}$ & 1118 & $\begin{array}{l}\text { Agujero rectangular repasado con sillares } \\
\text { en muro norte ábside norte. }\end{array}$ & 129 & 100 \\
\hline & & $\begin{array}{l}\text { Camarín, retablo mayor y } \\
\text { altares secundarios }\end{array}$ & 1128 & $\begin{array}{l}\text { Nicho en madera policromada en ábside } \\
\text { sur. }\end{array}$ & 123 & 100 \\
\hline & & $\begin{array}{l}\text { Camarín, retablo mayor y } \\
\text { altares secundarios }\end{array}$ & 1184 & Huellas de retablos en ábsides laterales. & 123 & 100 \\
\hline \multirow[t]{4}{*}{ VI } & 115 & Púlpitos & 1141 & $\begin{array}{l}\text { Cortes de semicolumnas en cara este de } \\
\text { pilares UE } 1140 .\end{array}$ & 153 & 100102 \\
\hline & & Púlpitos & 1145 & Corte longitudinal en pilar sur arquería. & 153 & 100 \\
\hline & & Púlpitos & 1147 & Corte longitudinal en pilar norte arquería. & & 100 \\
\hline & & Púlpitos & 1148 & $\begin{array}{l}\text { Corte semicolumna arco nave central } \\
\text { acceso transepto. }\end{array}$ & & 100 \\
\hline VI & 116 & $\begin{array}{l}\text { Hueco con reja en pilar } \\
\text { primer tramo norte }\end{array}$ & 1168 & $\begin{array}{l}\text { Agujero cuadrado con reja abierto en } \\
\text { pilar noreste nave central. }\end{array}$ & & 100 \\
\hline \multirow[t]{2}{*}{ VI } & 128 & $\begin{array}{l}\text { Grieta por apertura nichos } \\
\text { en ábside norte }\end{array}$ & 1008 & $\begin{array}{l}\text { Grieta vertical en paño sur del ábside } \\
\text { norte. }\end{array}$ & & 100 \\
\hline & & $\begin{array}{l}\text { Grieta por apertura nichos } \\
\text { en ábside norte }\end{array}$ & 1022 & $\begin{array}{l}\text { Grieta que recorre la cara norte del } \\
\text { ábside norte. }\end{array}$ & 129154 & 100 \\
\hline VI & 134 & $\begin{array}{l}\text { Ruina cámara suprábsidal } \\
\text { meridional }\end{array}$ & 1040 & Relleno de aspillera en tramo recto sur. & & 102 \\
\hline \multirow[t]{2}{*}{ VI } & 138 & $\begin{array}{l}\text { Ampliación ventanas } \\
\text { transepto }\end{array}$ & 1053 & $\begin{array}{l}\text { Roturas en ventana baja de testero } \\
\text { transepto norte. }\end{array}$ & 155 & 102 \\
\hline & & $\begin{array}{l}\text { Ampliación ventanas } \\
\text { transepto }\end{array}$ & 1122 & $\begin{array}{l}\text { Reforma de ventanas testeros sur y norte } \\
\text { transepto. Ampliación de luz. }\end{array}$ & 174 & 102 \\
\hline VI & 139 & $\begin{array}{l}\text { Enlucido cámara } \\
\text { suprábsidal }\end{array}$ & 1170 & Enlucidos interior cámara UE1169. & 133 & 102148 \\
\hline
\end{tabular}




\begin{tabular}{|c|c|c|c|c|c|c|}
\hline $\mathbf{P}$ & Act & Nombre Act & $\mathbf{U E}$ & Nombre UE & Ant a Act & Post a Act \\
\hline \multirow[t]{3}{*}{ VI } & 140 & $\begin{array}{l}\text { Cortes basas primer tramo } \\
\text { naves laterales }\end{array}$ & 1126 & $\begin{array}{l}\text { Cortes de medias columnas en arco nave } \\
\text { norte y transepto. }\end{array}$ & & 100 \\
\hline & & $\begin{array}{l}\text { Cortes basas primer tramo } \\
\text { naves laterales }\end{array}$ & 1138 & $\begin{array}{l}\text { Cortes de medias columnas de arco paso } \\
\text { nave sur a transepto. }\end{array}$ & 153 & 100 \\
\hline & & $\begin{array}{l}\text { Cortes basas primer tramo } \\
\text { naves laterales }\end{array}$ & 1142 & Cortes basas circulares pilares UE 1140 . & & 100 \\
\hline VI & 141 & $\begin{array}{l}\text { Ampliación luz ventana } \\
\text { ábside norte }\end{array}$ & 1020 & $\begin{array}{l}\text { Reparación en parte superior de jambas } \\
\text { de ventana de ábside norte. }\end{array}$ & 153154 & 100 \\
\hline \multirow[t]{2}{*}{ VI } & 142 & $\begin{array}{l}\text { Edificación y su cubierta } \\
\text { adosada a la nave sur }\end{array}$ & 1045 & $\begin{array}{l}\text { Agujeros y restos mortero esquina } \\
\text { suroeste. }\end{array}$ & 153 & 100 \\
\hline & & $\begin{array}{l}\text { Edificación y su cubierta } \\
\text { adosada a la nave sur }\end{array}$ & 1080 & $\begin{array}{l}\text { Restos de cubierta con tejas de piedra en } \\
\text { muro oeste transepto sur. }\end{array}$ & & 102104 \\
\hline \multirow[t]{2}{*}{ VI } & 143 & $\begin{array}{l}\text { Estructura adosada } \\
\text { transepto sur con elementos } \\
\text { metálicos y madera } \\
\text { asociados }\end{array}$ & 1041 & $\begin{array}{l}\text { Línea de tornapuntas en parte inferior } \\
\text { transepto sur exterior. }\end{array}$ & & 100 \\
\hline & & $\begin{array}{l}\text { Estructura adosada } \\
\text { transepto sur con elementos } \\
\text { metálicos y madera } \\
\text { asociados }\end{array}$ & 1043 & $\begin{array}{l}\text { Tacos de madera y puntas de hierro } \\
\text { hiladas } 6^{\mathrm{a}} \text { y } 7^{\mathrm{a}} \text { transepto sur. }\end{array}$ & & 100 \\
\hline \multirow[t]{2}{*}{ VI } & 147 & $\begin{array}{l}\text { Elevación presbiterio y } \\
\text { barandillas laterales }\end{array}$ & 1104 & $\begin{array}{l}\text { Agujeros en intradós oriental arcos UE } \\
1103 .\end{array}$ & & 107 \\
\hline & & $\begin{array}{l}\text { Elevación presbiterio y } \\
\text { barandillas laterales }\end{array}$ & 1106 & $\begin{array}{l}\text { Elevación del presbiterio y de ábside } \\
\text { central. }\end{array}$ & 174177 & 100107 \\
\hline \multirow[t]{2}{*}{ VI } & 162 & Credencia & 1113 & $\begin{array}{l}\text { Agujero rectangular junto a jamba norte } \\
\text { arco norte. }\end{array}$ & 173 & 100 \\
\hline & & Credencia & 1132 & $\begin{array}{l}\text { Agujero tramo recto, lado sur, ábside } \\
\text { meridional. }\end{array}$ & 173 & 100 \\
\hline \multirow[t]{4}{*}{ VII } & 119 & $\begin{array}{l}\text { Reparación ruina esquina } \\
\text { noroeste del aula }\end{array}$ & 1072 & $\begin{array}{l}\text { Fábrica de mampostería y ladrillo en } \\
\text { extremo occidental nave norte, exterior. }\end{array}$ & 136137156 & 119 \\
\hline & & $\begin{array}{l}\text { Reparación ruina esquina } \\
\text { noroeste del aula }\end{array}$ & 1074 & $\begin{array}{l}\text { Tornapunta en esquina inferior este de } \\
\text { UE } 1072 \text {. }\end{array}$ & & \\
\hline & & $\begin{array}{l}\text { Reparación ruina esquina } \\
\text { noroeste del aula }\end{array}$ & 1091 & Cuerpo superior del ángulo noroeste. & & 119 \\
\hline & & $\begin{array}{l}\text { Reparación ruina esquina } \\
\text { noroeste del aula }\end{array}$ & 1181 & $\begin{array}{l}\text { Corte sobre UE } 1075 \text { esquina noroeste } \\
\text { fachada. }\end{array}$ & 119136 & 111 \\
\hline VII & 120 & $\begin{array}{l}\text { Reparación en esquina } \\
\text { suroeste del exterior del } \\
\text { aula }\end{array}$ & 1089 & $\begin{array}{l}\text { Corte y reparación en revestimiento de } \\
\text { mortero y teja en esquina suroeste de } \\
\text { nave central. }\end{array}$ & & 111 \\
\hline VII & 121 & $\begin{array}{l}\text { Reparación ventana } \\
\text { occidental fachada sur nave } \\
\text { central }\end{array}$ & 1088 & $\begin{array}{l}\text { Reparación con ladrillo en zona } \\
\text { occidental en extremo oeste de nave } \\
\text { central exterior sur. }\end{array}$ & & 111 \\
\hline VII & 122 & Fachada meridional & 1081 & $\begin{array}{l}\text { Obras con placas de sillería en dos } \\
\text { tercios del lateral sur incluida portada. }\end{array}$ & & 100102111 \\
\hline
\end{tabular}




\begin{tabular}{|c|c|c|c|c|c|c|}
\hline $\mathbf{P}$ & Act & Nombre Act & $\mathbf{U E}$ & Nombre UE & Ant a Act & Post a Act \\
\hline & & Fachada meridional & 1155 & $\begin{array}{l}\text { Muro mampostería que cierra fondo } \\
\text { arcosolio. }\end{array}$ & & 100101 \\
\hline \multirow[t]{2}{*}{ VII } & 123 & Retablos ábsides laterales & 1115 & Altar y retablo en piedra del ábside norte. & & 113 \\
\hline & & Retablos ábsides laterales & 1127 & Altar y retablo en ábside sur. & & 113 \\
\hline \multirow[t]{3}{*}{ VII } & 124 & Cimborrio & 1079 & Esquina suroeste del cimborrio. & 132152 & \\
\hline & & Cimborrio & 1150 & Ménsulas blasonadas cimborrio.. & 153174 & 100102 \\
\hline & & Cimborrio & 1151 & $\begin{array}{l}\text { Muros cimborrio y bóveda estrellada } \\
\text { crucero. }\end{array}$ & 153 & 100102 \\
\hline VII & 125 & $\begin{array}{l}\text { Arco y capiteles interiores } \\
\text { capilla norte }\end{array}$ & 1163 & $\begin{array}{l}\text { Reposición moderna de capiteles y } \\
\text { arquivoltas de acceso a capilla gótica. }\end{array}$ & & 109 \\
\hline \multirow[t]{2}{*}{ VII } & 126 & Canecillos ábsides laterales & 1001 & $\begin{array}{l}\text { Remate de canecillos y cornisa del ábside } \\
\text { sur. }\end{array}$ & 154 & 100 \\
\hline & & Canecillos ábsides laterales & 1002 & $\begin{array}{l}\text { Remate de canecillos y cornisa ábside } \\
\text { norte. }\end{array}$ & & 100 \\
\hline \multirow[t]{2}{*}{ VII } & 129 & $\begin{array}{l}\text { Apertura ventana ábside } \\
\text { norte }\end{array}$ & 1021 & $\begin{array}{l}\text { Agujero tres sillares verticales cara norte } \\
\text { ábside norte. }\end{array}$ & & 100128 \\
\hline & & $\begin{array}{l}\text { Apertura ventana ábside } \\
\text { norte }\end{array}$ & 1119 & Relleno de UE 1119. & & 113 \\
\hline VII & 131 & Cubierta antigua cabecera & 1035 & Rozas de cubiertas sobre ábsides. & & 102132 \\
\hline \multirow[t]{4}{*}{ VII } & 132 & $\begin{array}{l}\text { Remate muros transepto y } \\
\text { ábside }\end{array}$ & 1036 & $\begin{array}{l}\text { Recrecido de mampostería y encadenado } \\
\text { de sillares. }\end{array}$ & 131152 & 102104112 \\
\hline & & $\begin{array}{l}\text { Remate muros transepto y } \\
\text { ábside }\end{array}$ & 1047 & $\begin{array}{l}\text { Agujero cuadrado en UE } 1036 \text { (parte } \\
\text { superior testero sur transepto). }\end{array}$ & & \\
\hline & & $\begin{array}{l}\text { Remate muros transepto y } \\
\text { ábside }\end{array}$ & 1058 & $\begin{array}{l}\text { Fábrica de mampuestos menudos en cara } \\
\text { oeste, exterior, transepto norte. }\end{array}$ & 152 & 104112 \\
\hline & & $\begin{array}{l}\text { Remate muros transepto y } \\
\text { ábside }\end{array}$ & 1182 & $\begin{array}{l}\text { Remate con cornisa frente oeste transepto } \\
\text { sur. }\end{array}$ & & 104124 \\
\hline \multirow[t]{2}{*}{ VII } & 135 & $\begin{array}{l}\text { Grieta bóveda y testero } \\
\text { transepto norte }\end{array}$ & 1049 & Grieta en testero norte transepto. & 155 & 100102 \\
\hline & & $\begin{array}{l}\text { Grieta bóveda y testero } \\
\text { transepto norte }\end{array}$ & 1123 & Grieta vertical en testero norte transepto. & & 100102 \\
\hline \multirow[t]{4}{*}{ VII } & 136 & $\begin{array}{l}\text { Reparación segundo tramo } \\
\text { nave norte }\end{array}$ & 1068 & $\begin{array}{l}\text { Chapado y tejaroz sobre ruina capilla } \\
\text { gótica. }\end{array}$ & & 109 \\
\hline & & $\begin{array}{l}\text { Reparación segundo tramo } \\
\text { nave norte }\end{array}$ & 1069 & $\begin{array}{l}\text { Lienzo de mampostería rematado en } \\
\text { cornisa pétrea exterior nave norte. }\end{array}$ & 156157 & 110119 \\
\hline & & $\begin{array}{l}\text { Reparación segundo tramo } \\
\text { nave norte }\end{array}$ & 1070 & $\begin{array}{l}\text { Línea de huecos ( } 7) \text { para vigas de madera } \\
\text { sobre UE } 1069 .\end{array}$ & & \\
\hline & & $\begin{array}{l}\text { Reparación segundo tramo } \\
\text { nave norte }\end{array}$ & 1179 & Línea vertical en muro de UE 1072. & & 119 \\
\hline VII & 137 & $\begin{array}{l}\text { Cegado ventana tercer } \\
\text { tramo nave norte }\end{array}$ & 1073 & Cegado de ventana inferior de UE 1072. & & 119 \\
\hline VII & 144 & Reposición campanas & 1055 & Roturas en intradós vanos campana. & & 112 \\
\hline
\end{tabular}




\begin{tabular}{|c|c|c|c|c|c|c|}
\hline $\mathbf{P}$ & Act & Nombre Act & UE & Nombre UE & Ant a Act & Post a Act \\
\hline VII & 146 & $\begin{array}{l}\text { Huella oblicua sobre } \\
\text { extremo occidental fachada } \\
\text { sur }\end{array}$ & 1084 & $\begin{array}{l}\text { Huella oblicua de cubierta en lienzo sur } \\
\text { de UE } 1075 .\end{array}$ & & 111 \\
\hline \multirow[t]{4}{*}{ VII } & 161 & Retablos testeros transepto & 1124 & $\begin{array}{l}\text { Huellas de retablo en testero norte } \\
\text { transepto. }\end{array}$ & & 100 \\
\hline & & Retablos testeros transepto & 1125 & $\begin{array}{l}\text { Nicho enmarcado con madera en testero } \\
\text { transepto norte. }\end{array}$ & & 100161 \\
\hline & & Retablos testeros transepto & 1135 & $\begin{array}{l}\text { Cegado con sillares arcosolio testero sur } \\
\text { transepto. }\end{array}$ & 174 & 117 \\
\hline & & Retablos testeros transepto & 1136 & Base para altar en testero sur transepto. & & 100 \\
\hline VII & 164 & $\begin{array}{l}\text { Pavimento interior acceso } \\
\text { original cegado }\end{array}$ & 1158 & $\begin{array}{l}\text { Pavimento con baldosas de ladrillo de } \\
\text { arcosolio y reparación en jamba derecha. }\end{array}$ & & 100 \\
\hline VII & 167 & Ruina cámara suprábsidal & 1172 & $\begin{array}{l}\text { Ruina extremo sur bóveda y muro } \\
\text { cámara UE } 1169 .\end{array}$ & & 102 \\
\hline \multirow[t]{2}{*}{ VII } & 169 & Apliques metálicos ábsides & 1097 & $\begin{array}{l}\text { Apliques metálicos en parte norte de } \\
\text { casquete absidial central. }\end{array}$ & & 100 \\
\hline & & Apliques metálicos ábsides & 1099 & $\begin{array}{l}\text { Argollas metálicas en parte alta del } \\
\text { ábside y clavos. }\end{array}$ & & 100 \\
\hline \multirow[t]{2}{*}{ VIII } & 149 & $\begin{array}{l}\text { Agujeros indeterminados } \\
\text { exterior ábside norte }\end{array}$ & 1016 & Pequeño agujero cuadrado. & & 100 \\
\hline & & $\begin{array}{l}\text { Agujeros indeterminados } \\
\text { exterior ábside norte }\end{array}$ & 1018 & $\begin{array}{l}\text { Pequeño agujero rectangular en cara sur } \\
\text { ábside norte. }\end{array}$ & 155 & 100 \\
\hline VIII & 150 & Cegada acceso capilla norte & 1067 & $\begin{array}{l}\text { Cegado de ladrillo arco acceso capilla } \\
\text { gótica. }\end{array}$ & & 109 \\
\hline VIII & 157 & $\begin{array}{l}\text { Agujero indefinido fachada } \\
\text { norte }\end{array}$ & 1071 & $\begin{array}{l}\text { Rotura irregular en lado oeste de UE } \\
1069 .\end{array}$ & & 136 \\
\hline VIII & 170 & $\begin{array}{l}\text { Cuadro conmemorativo } \\
\text { construcción capilla norte }\end{array}$ & 1167 & $\begin{array}{l}\text { Pareja de clavos junto a puerta de acceso } \\
\text { a capilla gótica. }\end{array}$ & 176 & \\
\hline VIII & 171 & Barandilla coro & 1166 & Barandilla de forja en coro alto. & 176 & \\
\hline \multirow[t]{2}{*}{ VIII } & 173 & $\begin{array}{l}\text { Reparaciones interior } \\
\text { cabecera enfoscado } \\
\text { superficie grosera }\end{array}$ & 1114 & Relleno de UE 1113. & & 162 \\
\hline & & $\begin{array}{l}\text { Reparaciones interior } \\
\text { cabecera enfoscado } \\
\text { superficie grosera }\end{array}$ & 1133 & Relleno de UE 1132. & & 162 \\
\hline IX & 151 & Cubiertas ábsides & 1003 & $\begin{array}{l}\text { Recrecido de ladrillo en parte superior } \\
\text { ábside central. }\end{array}$ & & 100 \\
\hline \multirow[t]{2}{*}{ IX } & 152 & $\begin{array}{l}\text { Alzados ladrillos sobre } \\
\text { transepto con su cubierta } \\
\text { y aula }\end{array}$ & 1064 & $\begin{array}{l}\text { Obra de ladrillo revestida de mortero que } \\
\text { une cimborrio y espadaña. }\end{array}$ & & 102112132 \\
\hline & & $\begin{array}{l}\text { Alzados ladrillos sobre } \\
\text { transepto con su cubierta } \\
\text { y aula }\end{array}$ & 1086 & $\begin{array}{l}\text { Lienzo de posible muro de mampostería } \\
\text { enfoscado en fachada sur de nave central. }\end{array}$ & & 104105111 \\
\hline
\end{tabular}




\begin{tabular}{|c|c|c|c|c|c|c|}
\hline $\mathbf{P}$ & Act & Nombre Act & UE & Nombre UE & Ant a Act & Post a Act \\
\hline & & $\begin{array}{l}\text { Alzados ladrillos sobre } \\
\text { transepto con su cubierta } \\
\text { y aula }\end{array}$ & 1090 & Enfoscado cara norte nave central. & & 111 \\
\hline & & $\begin{array}{l}\text { Alzados ladrillos sobre } \\
\text { transepto con su cubierta } \\
\text { y aula }\end{array}$ & 1177 & $\begin{array}{l}\text { Estructura ladrillo hueco y madera. } \\
\text { Cubiertas teja. }\end{array}$ & & $\begin{array}{l}102112124 \\
132\end{array}$ \\
\hline \multirow[t]{11}{*}{ IX } & 153 & $\begin{array}{l}\text { Recomposición ventanas } \\
\text { ábside y otras reformas en } \\
\text { ábside y transepto }\end{array}$ & 1006 & $\begin{array}{l}\text { Restauración con sillares abujardados y } \\
\text { tizones. }\end{array}$ & 154 & $\begin{array}{l}113114142 \\
153\end{array}$ \\
\hline & & $\begin{array}{l}\text { Recomposición ventanas } \\
\text { ábside y otras reformas en } \\
\text { ábside y transepto }\end{array}$ & 1007 & $\begin{array}{l}\text { Cierres de alabastro de ventanas } \\
\text { absidiales. }\end{array}$ & & 100153 \\
\hline & & $\begin{array}{l}\text { Recomposición ventanas } \\
\text { ábside y otras reformas en } \\
\text { ábside y transepto }\end{array}$ & 1028 & $\begin{array}{l}\text { Agujeros a modo de tizones en parte } \\
\text { superior de ábside sur y presbiterio. }\end{array}$ & 153 & 100 \\
\hline & & $\begin{array}{l}\text { Recomposición ventanas } \\
\text { ábside y otras reformas en } \\
\text { ábside y transepto }\end{array}$ & 1093 & $\begin{array}{l}\text { Reparación contemporánea con mortero } \\
\text { arenoso y despiece fingido. }\end{array}$ & & $\begin{array}{lll}100 & 107 & 113 \\
114 & 115 & 118 \\
140 & 148 & 159 \\
161 & 172 & \end{array}$ \\
\hline & & $\begin{array}{l}\text { Recomposición ventanas } \\
\text { ábside y otras reformas en } \\
\text { ábside y transepto }\end{array}$ & 1094 & $\begin{array}{l}\text { Apertura de ventanas interiores del } \\
\text { ábside central. }\end{array}$ & 174 & 100 \\
\hline & & $\begin{array}{l}\text { Recomposición ventanas } \\
\text { ábside y otras reformas en } \\
\text { ábside y transepto }\end{array}$ & 1131 & Cegado interior ventana UE 1130. & & 114 \\
\hline & & $\begin{array}{l}\text { Recomposición ventanas } \\
\text { ábside y otras reformas en } \\
\text { ábside y transepto }\end{array}$ & 1134 & Enlucido que recubre la base del husillo. & & 100118 \\
\hline & & $\begin{array}{l}\text { Recomposición ventanas } \\
\text { ábside y otras reformas en } \\
\text { ábside y transepto }\end{array}$ & 1137 & Peldaños de escalera de acceso husillo. & & 100 \\
\hline & & $\begin{array}{l}\text { Recomposición ventanas } \\
\text { ábside y otras reformas en } \\
\text { ábside y transepto }\end{array}$ & 1146 & Reparación de UE 1145. & 174 & 115 \\
\hline & & $\begin{array}{l}\text { Recomposición ventanas } \\
\text { ábside y otras reformas en } \\
\text { ábside y transepto }\end{array}$ & 1152 & $\begin{array}{l}\text { Pintura que recubre interior cimborrio } \\
\text { imitando piedra. }\end{array}$ & & 102124 \\
\hline & & $\begin{array}{l}\text { Recomposición ventanas } \\
\text { ábside y otras reformas en } \\
\text { ábside y transepto }\end{array}$ & 1161 & Relleno de UE 1160. & & 118 \\
\hline \multirow[t]{3}{*}{ IX } & 154 & $\begin{array}{l}\text { Reparación mortero exterior } \\
\text { cabecera (año 1953) }\end{array}$ & 1037 & $\begin{array}{l}\text { Rejuntado de restauración con mortero } \\
\text { arenoso. }\end{array}$ & & $\begin{array}{l}100113114 \\
126128141 \\
153\end{array}$ \\
\hline & & $\begin{array}{l}\text { Reparación mortero exterior } \\
\text { cabecera (año 1953) }\end{array}$ & 1042 & Relleno de UE 1041. & & 100 \\
\hline & & $\begin{array}{l}\text { Reparación mortero exterior } \\
\text { cabecera (año 1953) }\end{array}$ & 1044 & $\begin{array}{l}\text { Reparación con mortero marrón («Año } \\
1953 ») \text {. }\end{array}$ & & 100 \\
\hline
\end{tabular}




\begin{tabular}{|c|c|c|c|c|c|c|}
\hline $\mathbf{P}$ & Act & Nombre Act & UE & Nombre UE & Ant a Act & Post a Act \\
\hline \multirow[t]{3}{*}{ IX } & 155 & $\begin{array}{l}\text { Reparación cemento } \\
\text { exterior cabecera }\end{array}$ & 1019 & Relleno de UE 1018. & & 149 \\
\hline & & $\begin{array}{l}\text { Reparación cemento } \\
\text { exterior cabecera }\end{array}$ & 1050 & $\begin{array}{l}\text { Reparación con cemento de UE } 1049 \text { y } \\
\text { zonas próximas. }\end{array}$ & & 135 \\
\hline & & $\begin{array}{l}\text { Reparación cemento } \\
\text { exterior cabecera }\end{array}$ & 1054 & Relleno de UE 1053. & & 138 \\
\hline IX & 156 & $\begin{array}{l}\text { Reparación desmonte muro } \\
\text { sobre fachada norte }\end{array}$ & 1180 & Relleno extremo muro UE 1069. & & 119136 \\
\hline \multirow[t]{3}{*}{ IX } & 174 & $\begin{array}{l}\text { Abujardado interior ábsides } \\
\text { y transepto }\end{array}$ & 1120 & $\begin{array}{l}\text { Cruces pintadas en muros laterales de } \\
\text { ábsides norte y sur. }\end{array}$ & & 100174 \\
\hline & & $\begin{array}{l}\text { Abujardado interior ábsides } \\
\text { y transepto }\end{array}$ & 1121 & $\begin{array}{l}\text { Rotura en el capitel del ábside norte, lado } \\
\text { norte. }\end{array}$ & & 100 \\
\hline & & $\begin{array}{l}\text { Abujardado interior ábsides } \\
\text { y transepto }\end{array}$ & 1178 & Abujardado y rejuntado. & 174 & $\begin{array}{l}100107112 \\
124138147 \\
153161\end{array}$ \\
\hline IX & 175 & $\begin{array}{l}\text { Restauración con mortero } \\
\text { fino }\end{array}$ & 1108 & $\begin{array}{l}\text { Reparaciones en aristas, basas y } \\
\text { paramentos de pilares embocadura } \\
\text { ábsides. }\end{array}$ & & $\begin{array}{l}100102114 \\
160\end{array}$ \\
\hline IX & 176 & $\begin{array}{l}\text { Cemento y pintura blanca } \\
\text { aula }\end{array}$ & 1165 & $\begin{array}{l}\text { Revestimiento de pintura y enlucido aula } \\
\text { y coro. }\end{array}$ & & 170171 \\
\hline IX & 177 & Cadena presbiterio & 1107 & $\begin{array}{l}\text { Agujero con argolla metálica cadena. } \\
\text { Sendos lados presbiterio. }\end{array}$ & & 107147 \\
\hline
\end{tabular}

\section{Apéndice II. Documentación ${ }^{36}$}

(Lectura y transcripción de Josemi Lorenzo Arribas, Proyecto Cultural Soria Románica)

1659, abril, 5 (ADO-S, Libro 38/33, f. 33r): Se le pasan en cuenta 50,5 fanegas de trigo y 6,5 reales que se dio a Juan de Medina por el empedrado que hizo en los portales de dicha iglesia.

1692, mayo, 8 (ADO-S, Libro 38/33, f. 177r): Y se le recibe en data 482 reales de vellón que son los mismos que se han gastado en dos púlpitos que se han hecho en dicha iglesia y un aderezo que se hizo en la sacristía así de todos materiales como de jornales...

\footnotetext{
36 La serie de libros de fábrica consultada en el ADO-S comprende: libro 38/33: Libro de carta cuenta. Inventario de las Parroquias unidas de Santa María de Campanario y de Santiago (1641-1728); Libro 38/34: Libro de carta cuenta. Inventario de las parroquias unidas de Santa maría de Campanario y de Santiago (1724-1784); Libro 38/35: Libro de carta cuenta. Inventario de las Parroquias unidas de Santa María de Campanario y de Santiago (1785-1832). Además se consultó el libro conservado en el Archivo Parroquial: Libro de cuenta y razón de la iglesia de Santa María de Campanario de Almazán (1861-1901).
}

1704, abril, 17 (ADO-S, Libro 38/33, f. 271v): Se le recibe en data 210 reales que son los mismos que se han gastado en el aderezo de la capilla del Santo Cristo y su retejo, y materiales...

1720, noviembre, 14 (ADO-S, Libro 38/33, ff. 256v-257r): Se le pasan en cuenta 651 reales y $22 \mathrm{mrs}$, los mismos que lo han importado el reparo que se hizo de un retejo general en los tejados de la iglesia y capilla del campanario, y de la casa que tiene en la calle de Santa Clara, cal, teja, agua y trabajo de los maestros y peones, y lo que se gastó en desmontar el tejado, la parte que se hundió por quiebra de las maderas y trabajo de cubierta de tabla, / lo que no se viese hasta la perfección de la obra que se está ejecutando.

1722, octubre, 26 (ADO-S, Libro 38/33, f. 363r): 126 reales y dos maravedíes que constó de recibos y libramientos de dicho señor cura haber pagado de Sebastián de Salguero, maestro de obras, por la que ejecutó en el coro de dicha iglesia y levantar la tribuna.

1738, noviembre, 23 (ADO-S, Libro 38/34, f. 84v): 95 reales que costaron las vidrieras para el camarín y coro de Nuestra Señora. 
1752, noviembre, 25 (ADO-S, Libro 38/34, ff. 150v-151r): Y por cuanto uno de los coros de esta parroquia se halla no con poca indecencia, lleno de huesos de los difuntos que se han enterrado en ella, manda $\mathrm{Su}$ Merced, que en el término de un mes se haga un osario (f. 151r) a que se trasladen todos los expresados huesos, dejando el templo con mayor aseo y decencia.

1757, enero, 31 (ADO-S, Libro 38/34, ff. 162v163r): Es data 166 reales que tuvo de costa el $¿$ ? y lucir el arco de la capilla antigua del Santo Cristo. || Es data 14 (f. 163r) 57 reales y $13 \mathrm{mrs}$ que se pagaron de jornales a Germán de la Sierra, Diego Solar y Luis Leonés, por el tiempo que trabajaron en componer la pared y cornisa y en desbolazar y renovar el tejado de la iglesia...

1762, diciembre, 30 (ADO-S, Libro 38/34, ff. 179v-180r): Es cargo 920 reales en que Gregorio y Fernando de la Sierra, maestros albañiles de esta villa, tajaron la piedra de mamposterías, sillería, que se vendió para una pared del palacio y procedía de la capilla del Santo Cristo, que por estar amenazando ruina se desmontó... || Es cargo 210 reales de la piedra de sillería de dicha capilla desmontada, que se vendió por su tasación al hospital de esta villa. || Es data 1.720 reales y $33 \mathrm{mrs}$ gastados en obras y / reparos que se han hecho en la iglesia y en el desmonte de dicha capilla es, a saber, una pared de mampostería en un lienzo que había de tapia antigua, y el retejo general de la iglesia uno y otro por Vicente Sierra, maestro albañil y compañeros, vecinos de esta villa, y el blanqueo en lo interior de la iglesia y aberturas de dos ventanas grandes con sus vidrieras y redes, hecho por Diego Solán, también maestro albañil...

1772, agosto, 3 (ADO-S, Libro 38/34, f. 215v): ... se componga la quiebra de las vigas que están encima del caracol asomado a la capilla de la pila bautismal subiendo un porte de ladrillo desde el esconce de machón para que reciba las cabezas de dichas vigas. || [Nota marginal:] Están ejecutadas todas las obras que mandó su merced.

1781, marzo, 1 (ADO-S, Libro 38/34, s.f., v): 590 reales de vellón que pagó de manos y materiales por el blanqueo general que se hizo en la iglesia, y picar unas piedras que sobresalían de los arcos. $\| 89$ reales que pagó de manos y materiales por la ventana que se abrió en la bóveda principal, por la vidriera y red que en ella se puso y hacer una buhardilla (guardilla) que le comunica la luz.

1781, mayo, 25 (ADO-S, Libro 38/34, s.f., r-rv-r-v): Copia de la licencia concedida por su Señoría Ilustrísima a don Bonifacio Zapata para la obra que a sus expensas ha hecho del embovedado de la iglesia de campanario y otras obras que fue preciso. [Carta del señor cura] don Francisco Javier Gómez de Segovia, cura de la parroquial de Santa María del Campanario de la villa de Almazán, puesto a los pies de Vuestra Ilustrísima con el mayor rendimiento dice que esta iglesia solamente está embovedada poco más de la mitad y lo restante toda de maderas, lo que dice notable deformidad a la hermosura y majestad de su crucero, notándose más este / defecto por ser esta iglesia en la que se hacen las funciones públicas de villa, cabildo y rogativas. Con esta imperfección y desigualdad ha continuado desde su primera construcción, de que no hay memoria, y proseguiría por no tener su fábrica caudales para ello; pero don Bonifacio Zapata, presbítero de esta villa y feligrés de esta parroquia ofrece concluir sus bóveda a su costa sin que quede gravada con carga alguna a su favor, a cuyo fin tiene ajustada esta obra en 11.000 reales con Gregorio Sierra, maestro de obras muy inteligente y conocido, quien otorgará escritura pública con las debidas seguridades, y dicho don Bonifacio de darle dicha cantidad cumpliendo aquel con las condiciones estipuladas de la planta que imita y sigue las tres naves de la obra antigua (...) 2 de septiembre de 1780. ॥ (f. v) [Carta del señor Don Bonifacio] ... he resuelto con el consentimiento, beneplácito y licencia de Vuestra Ilustrísima embovedar de medio abajo que hoy se halla con techo de madera la iglesia de Nuestra Señora del Campanario de esta villa (...) lo tengo tratado con Gregorio La Sierra, maestro de este obispado y hombre inteligente y convenido y ajustados en 1.000 ducados, y no faltándome más que la venia y consentimiento de Vuestra Ilustrísima, espero de su gran cristiandad y caridad apruebe mi pensamiento (...) / Almazán y septiembre de 1780. || [Decreto] Sigüenza, 5 de septiembre de 1780 . Concedemos a don Bonifacio Zapata, la licencia que solicita aprobando su celo y caridad. Juan Obispo de Sigüenza. || [Recibo de la obra principal] Confieso yo, Gregorio la Sierra, vecino de esta Villa de Almazán, maestro alarife de cantería y albañilería, que en atención a que con el señor don Bonifacio Zapata, presbítero en ella y feligrés de la iglesia del Campanario, y su unida de Santiago, tenía tratado de embovedar dicha iglesia, por precio y cantidad de 1.000 ducados que hacen 11.000 reales de vellón, por hallarse sumamente independiente y artesonada de madera, y que respecto que dicho señor don Bonifacio consiguió la licencia correspondiente de su Ilustrísima para que no le fuera puesto embarazo, a cuya obra se dio principio el día 10 de septiembre de 1780 y se concluyó en 30 de marzo de 81 , he recibido del referido señor don Bonifacio Zapata los 11.000 reales de vellón (...) Almazán y 
mayo 25 de 1781. Gregorio la Sierra. \| (f. v) [Otro de la ocurrida después] Asimismo yo, el dicho Gregorio la Sierra, confieso haber recibido del señor don Bonifacio Zapata, presbítero, 900 reales de vellón, en 225 pesetas de a 4 reales, porque, hallando que habiéndose hecho el embovedado quedaba imperfecta la obra si no se hacía la escalera del coro alto y el de abajo se la hacía cielo raso, molduras media caña y su florón al medio, que fue en lo que nos convenimos y de hecho se hizo y ejecutó así. Y de haber recibido dicho dinero y haberse concluido la obra doy el presente recibo en dicho a 25 de mayo a 1781 años. Gregorio la Sierra.

1795, noviembre, 20 (ADO-S, Libro 38/35, s.f., v): 550 reales pagados a Vicente Gómez, maestro carpintero, según su recibo, por componer la sillería del coro, sus tarimas, confesionarios, guardavoz y una de las puertas, principio de la iglesia.

1799, noviembre, 25 (ADO-S, Libro 38/35, s.f., r-v): 6.686 reales que, según recibo y libramiento de $\mathrm{Su}$ Merced, entregó para empezar a soportar los gastos de las obras de la iglesia de que abajo se hará mención. ॥ $34.988 \mathrm{mrs}$ y $2 \mathrm{mrs}$ que además a la partida anterior se han gastado en la nueva obra incoada, y no concluida, de alargar la iglesia, y otras cosas que se expresaron, que juntas las dos hacen 41.674 reales y 2 mrs invertidos en esta forma: 11.885 reales y $10 \mathrm{mrs}$ en hacer el granero contiguo a la iglesia, puerta que se abrió para la sacristía, aguamanil nuevo que se hizo, espejos y cuadros que se compraron para su adorno, rasgar las ventanas altas en el crucero, águilas del presbiterio, abrir el pozo y sacar piedra para la / obra, cortinas y barritas y cuerdas para las ventanas; 600 reales que costó el blanqueo de toda la iglesia, excepto la obra nueva que no se ha concluido; 300 reales que costaron de enyugar las campanas; 1.200 reales que costó cerrar un prado y otros reparos hechos en la heredad y bienes de la Riba de Escalote; 3.508 reales que costaron 5 casullas de varios colores y una cortina para la Virgen en su trono; 24.280 reales y 26 mrs restantes en la obra empezada para alargar la iglesia y bóvedas nuevas ya ejecutadas, cuyas partidas componen la dicha total de 41.674 reales y 2 mrs, según aparece de las listas y asientos que ha llevado el señor cura y mediante ir datados los 6.686 reales, que por primera partida suplió el mayordomo, es última partida de obras los derechos.

1807, enero, 7 (ADO-S, Libro 38/35, s.f., v-r): 1.600 reales de vellón que pagó por el coste que tuvo el rasgar y hacer la ventana de la iglesia en la capilla mayor del lado de la Epístola, y encima de la sacristía, reparo hecho en el tejado de la nave pequeña arrimado a el caracol de la torre que se había hundido, / composición de las tapias detrás de la sacristía, excavación de arena y piedra que se sacó de la calle contigua a la conejera, abrir otra ventana de la capilla mayor al lado del Cierzo, piedra sillar que se sacó encima de la capilla del Carmen, y construcción de un pozo arrimado a la iglesia para depósito de las aguas para la obra de ellas. || Se le pasan en data 13.308 reales y $18 \mathrm{mrs}$ que, en virtud de libramientos dados por Su Merced, ha entregado y pagado para los materiales y jornales de la obra de la iglesia, en alargarle la nave y nueva torre que se ha principiado a fabricar.

1814, julio, 27 (ADO-S, Libro 38/35, s.f., r-v): Son data 2.921 reales y $31 \mathrm{mrs}$ que ha suplido en la obra del retejo de la iglesia, con materiales de / cal, tierra, piedra, agua, jornales de maestros y oficiales, yeso para el cielo raso de la sacristía, ladrillo para levantar la esquina del pórtico de la iglesia, una viga para el tejado del mismo, pórtico y cerrar con tajos a los dos arcos del embaldosado del cuarto bajo de la escalera del coro, desarmar la vidriera grande de él, teja y otros reparos que constaron de asiento pormenor.

1888, diciembre, 31 (Archivo de la Casa parroquial, Libro de carta y razón de Santa María de Campanario, 1861-1900, f. 42r): De la obra del portegado, según recibo, 242 reales.

1897, diciembre, 23 (Archivo de la Casa parroquial, Libro de carta y razón de Santa María de Campanario, 1861-1900, f. 52v): Lo son al maestro carpintero y albañil de la obra del presbiterio y altar mayor, pagando el Ayuntamiento 559 pesetas y la iglesia según la autorización que aconsejaría solo 268 pesetas. 